\section{Unintended Pregnancy, Abortion and Postabortion Care In Gujarat, India-2015}

Harihar Sahoo, Melissa Stillman, Jennifer J. Frost and Shveta Kalyanwala

\section{Key Points}

- An estimated 811,800 abortions occurred in Gujarat in 2015. These included safe and unsafe abortions, and those taking place both in health facilities and in other settings. The state's abortion rate was 48 abortions per 1,000 women of reproductive age.

- The large majority of abortions $(80 \%$, or 647,900$)$ took place in nonfacility settings using medical methods of abortion, and $5 \%(41,900)$ were performed outside of health facilities using other methods.

- Only $15 \%$ of abortions $(122,000)$ occurred in health facilities. Private facilities provided most facility-based terminations (81\%).

- An estimated 2,294 facilities in Gujarat provided abortion-related care (induced abortion, postabortion care or both types of services) in 2015; $21 \%$ were public and $79 \%$ were private. Sixty-nine percent of public facilities reported offering no abortion-related care.

- The vast majority (96\%) of health facility abortions took place in the first trimester of pregnancy (up to 12 weeks' gestation), and two-thirds (68\%) occurred at less than eight weeks' gestation. More than half of all facility-based abortions were performed surgically using manual or electric vacuum aspiration (31\%) or either dilatation and evacuation or dilatation and curettage (28\%).

- More than half of reproductive-aged women (56\%) live in rural areas, where only a minority (31\%) of facilities providing any abortionrelated services were located. Among facilities that offered such services, only $3 \%$ of public hospitals and $18 \%$ of private hospitals-the facilities best equipped to handle severe complications or later-term abortions-were located in rural areas.

More than half (53\%) of pregnancies occurring in Gujarat in 2015 were unintended. The majority (64\%) of these unintended pregnancies ended in an abortion.

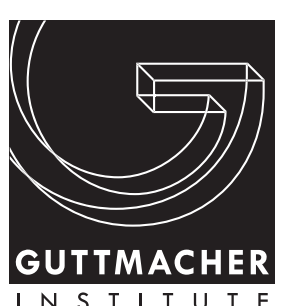

I N S T I T U T E

\section{POPULATION} COUNCIL

Ideas. Evidence. Impact.

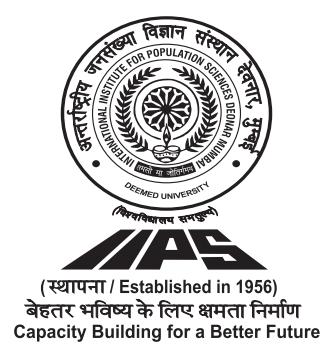




\title{
Unintended Pregnancy, Abortion and Postabortion Care in Gujarat, India-2015
}

\author{
Harihar Sahoo, Melissa Stillman, Jennifer J. Frost and Shveta Kalyanwala
}

\section{ACKNOWLEDGMENTS}

This report is part of a larger study titled Unintended Pregnancy and Abortion in India (UPAI), which was conducted to provide much-needed information on the incidence of induced abortion and pregnancy, as well as access to and quality of safe abortion services, in six Indian states.

The authors thank the technical advisory committee that provided guidance throughout the project. It was chaired by Purushottam Kulkarni, formerly of Jawaharlal Nehru University, and its members were Dinesh Agrawal, independent consultant; Sushanta Banerjee, Ipas Development Foundation (IDF); Manju Chhugani, Jamia Hamdard University; Kurus Coyaji, King Edward Memorial Hospital; Ravi Duggal, International Budget Partnership; Sharad lyengar, Action Research and Training for Health; Sunitha Krishnan, St. John's National Academy of Health Sciences; Mala Ramanathan, Sree Chitra Tirunal Institute for Medical Sciences and Technology; T.K. Roy, independent consultant; Nozer Sheriar, Hinduja Healthcare Surgical and Holy Family Hospitals; Leela Visaria, Gujarat Institute of Development Research; and Ministry of Health and Family Welfare representatives Dinesh Biswal, Veena Dhawan, Sumita Ghosh, Vandana Gurnani, Manoj Jhalani, Rakesh Kumar, Manisha Malhotra, C.K. Mishra and Arun Kumar Panda.

The authors also thank the following colleagues from other organizations who provided guidance or information along the way: Kalpana Apte and Armin Neogi, Family Planning Association of India; Alok Banerjee and Sudha Tewari, Parivar Seva Santha; Amit Bhanot, Mahesh Kalra and Hanimi Reddy Modugu, Hindustan Latex Family Planning Promotion Trust; Sunitha Bhat and Vivek Malhotra, Population Health Service India; Todd Callahan, Christopher Purdy and Michele
Thorburn, DKT International; V.S. Chandrashekhar, Foundation for Reproductive Health Services India; Kathryn Church and Barbara Reichwein, Marie Stopes International, London; Ram Parker, Janani; Mahesh Puri, Center for Research on Environment Health and Population Activities; Faujdar Ram, formerly of the International Institute for Population Sciences (IIPS); and Usha Ram and L. Ladusingh, IIPS.

In addition, the authors are grateful for the suggestions and advice offered by the following colleagues who reviewed one or more drafts of the manuscript: Sandhya Barge, Center for Operations Research and Training; Alka Barua, independent consultant; and Nozer Sheriar.

This report was written by Harihar Sahoo, IIPS; Melissa Stillman and Jennifer J. Frost, Guttmacher Institute; and Shveta Kalyanwala, independent consultant. It was edited by Susan London and Haley Ball. The authors thank the following Guttmacher colleagues for their comments and help in developing this report: Akinrinola Bankole, Sneha Barot and Gustavo Suarez, for reviewing a draft of the report; and Marjorie Crowell, Shivani Kochhar and Zoe Pleasure, for research support.

This report was made possible by grants to the Guttmacher Institute from the Government of UK Department for International Development (until 2015), the David and Lucile Packard Foundation, the John D. and Catherine T. MacArthur Foundation, and the Ford Foundation. The Guttmacher Institute gratefully acknowledges the unrestricted funding it receives from individuals and foundations-including major grants from the William and Flora Hewlett Foundation and the David and Lucile Packard Foundation-which undergirds all of the Institute's work. The views expressed do not necessarily reflect the positions or policies of the donors.

(C) Guttmacher Institute, 2018

Suggested citation: Sahoo H et al., Unintended Pregnancy, Abortion and Postabortion Care in Gujarat, India-2015, New York: Guttmacher Institute, 2018,

https://www.guttmacher.org/report/unintended-pregnancy-abortion-postabortion-care-gujarat-india-2015.

\section{www.guttmacher.org}




\section{Table of Contents}

CONTEXT OF ABORTION IN INDIA AND THE STATE OF GUJARAT …….......... 4

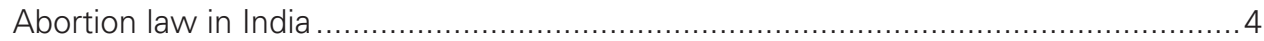

Sexual and reproductive health and abortion in Gujarat ......................................... 5

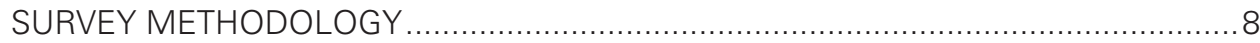

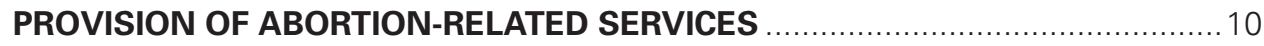

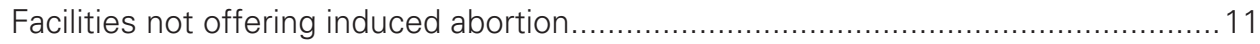

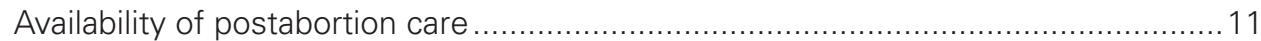

INDUCED ABORTION SERVICES PROVIDED IN FACILITIES .........................12

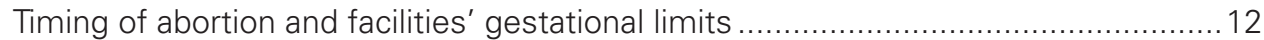

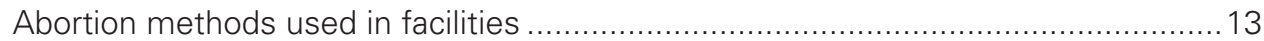

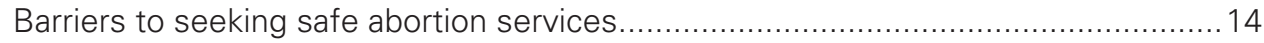

PROVISION OF POSTABORTION CARE

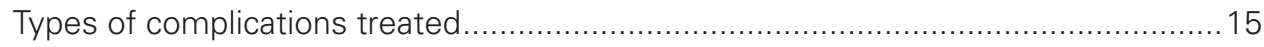

Number of women treated for postabortion complications .................................. 17

INCIDENCE OF INDUCED ABORTION AND UNINTENDED PREGNANCY _.........18

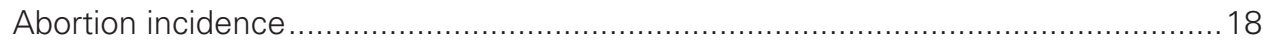

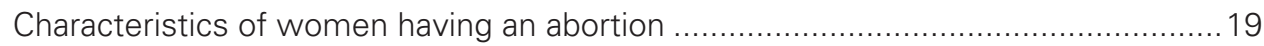

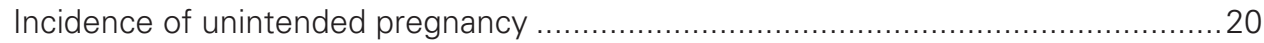

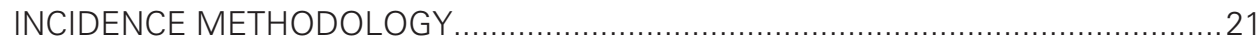

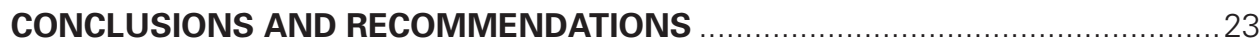

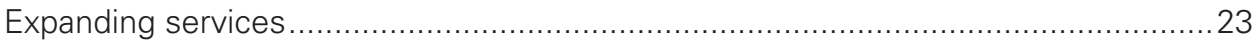

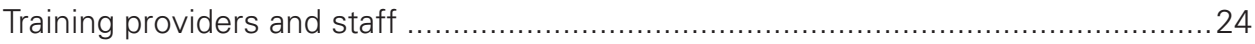

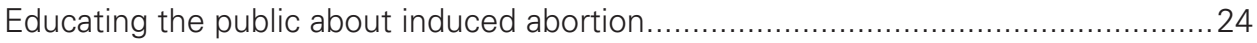

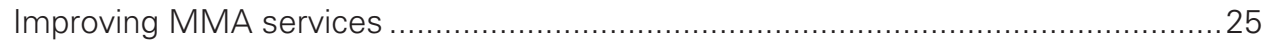

Improving access to and quality of postabortion care services ..............................25

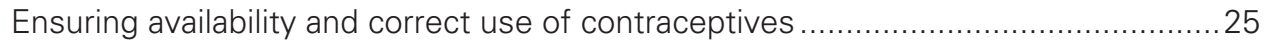

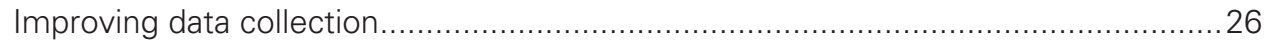

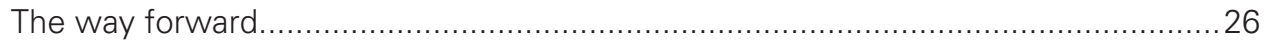

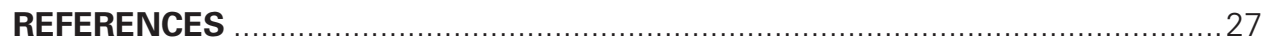

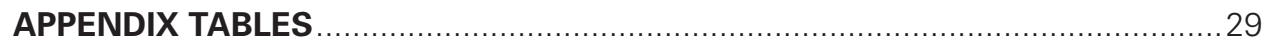




\section{Context of Abortion in India and The State of Gujarat}

A Ithough abortion is legal in India, evidence on how many abortions occur and under what circumstances they are performed is limited. Official incidence statistics come from the Family Welfare Yearbook published by the Ministry of Health and Family Welfare (MoHFW), Government of India; these statistics underestimate abortion incidence because coverage of facility-based services is incomplete and many abortions take place outside of facility settings. ${ }^{1}$ The most recent (and most commonly cited) study to have estimated abortion incidence in India was based on a small sample of facilities and likely underestimated the true magnitude. ${ }^{2}$ The data in this study are also now more than 15 years old, and demographic factors that influence abortion and conditions surrounding its provision have changed markedly over this period. ${ }^{3-5}$ Until now, the country has lacked a large-scale study of abortion service provision in both public and private health facilities that documents the care provided and its quality, captures nonfacility abortions, and gives reliable estimates of the incidence of abortion and unintended pregnancy.

To fill this gap in data, we undertook a rigorous study, titled Unintended Pregnancy and Abortion in India (UPAI), which uses a modified version of the widely used abortion incidence complications methodology. ${ }^{6-8}$ It covers six states of India-Assam, Bihar, Gujarat, Madhya Pradesh, Uttar Pradesh and Tamil Nadu-that together account for about $45 \%$ of the country's population and were chosen to represent each region of the country. For each state, the study

- provides representative, in-depth information on the characteristics of abortion-related services (induced abortion and postabortion care) provided by each type of public- and private-sector facility in 2015;

- uses facility-based abortion data from the six states and national data on medical methods of abortion (MMA) sales to estimate abortion incidence; and

- uses abortion incidence data to estimate levels of unintended pregnancy, an important indicator of women's ability to regulate their fertility.

This report focuses on Gujarat, first providing detailed findings on facility-based abortion and postabortion services in the state, then using these and other data to formulate estimates of the incidence of abortion and unintended pregnancy. In the final section of the report, we offer recommendations to facilitate planning for improvements in the accessibility and provision of safe, high-quality abortion services. Visit https://www.guttmacher.org/report/unintended pregnancy-abortion-postabortion-care-gujarat-india-2015 to find more resources produced as part of this study.

\section{Abortion law in India}

Induced abortion has been legal in India on a broad range of grounds since the Medical Termination of Pregnancy (MTP) Act was passed in 1971. According to this law, abortion is permitted up to 20 weeks' gestation when it is necessary to save a woman's life or protect her physical or mental health, and in cases of economic or social necessity, rape, contraceptive failure among married couples and fetal anomaly. ${ }^{9}$ Pregnancies beyond 20 weeks may be terminated in cases of life endangerment. The MTP Act mandates that abortions take place in safe and hygienic conditions at approved facilities and be performed by certified providers. Providers eligible for certification are limited to obstetrician-gynecologists or doctors with a bachelor of medicine, bachelor of surgery (MBBS) degree who have undergone MTP training.

All public facilities at the primary health centre (PHC) level or higher are approved to provide abortions, as long as they have a certified provider on staff. Facilities lacking the necessary equipment are expected to have referral linkages to higher-level sites. Private facilities, on the other hand, must become registered to provide legal abortion services, a process that entails meeting criteria specified by the MTP Act. Registration is difficult, in part because the District Level Committees responsible for approving private facilities do not exist in some areas and may meet infrequently in others. Several small-scale studies have found that many private facilities that provide abortion services are not approved to do so. ${ }^{10-13}$ However, lack of registration does not imply that the abortions provided in those facilities are unsafe, as unregistered facilities may have qualified, trained staff performing safe abortions.

The MTP Act of 1971 has been amended to address advances in abortion methods, and these and other policy changes have contributed to expanding access to MMA, which, in India, refers primarily to the use of a combined regimen of misoprostol and mifepristone (whether packaged separately or together in a "combipack"). A 2002 amendment permitted the provision of MMA by abortion-certified 
doctors in facilities not specifically approved to offer abortions, as long as these facilities have referral linkages to a facility approved to provide abortion (thus facilitating prompt action in case of complications), and a 2003 amendment allowed for the use of MMA for pregnancy terminations up to seven weeks' gestation. ${ }^{* 15-17}$ The amendments also attempted to improve the process of registering private facilities by speeding it up and shifting responsibility from the state to District Level Committees. In 2008, the combipack, which contains $200 \mathrm{mg}$ of mifepristone and $800 \mathrm{mcg}$ of misoprostol, was approved in India. ${ }^{18}$ Amendments to the MTP Act have been proposed that would expand the range of providers legally able to offer early first-trimester abortion to include nurses and auxiliary nurse midwives (ANMs), as well as practitioners trained in Indian systems of medicine with recognized qualifications; allow terminations at a woman's request up to 12 weeks' gestation; allow abortion in cases of contraceptive failure for all women and couples, regardless of marital status; increase the gestational age limit for abortion to 24 weeks for certain vulnerable groups; and remove the gestational age limit for terminations sought because of diagnosed fetal abnormality. ${ }^{19}$ At the time of this writing, none of these proposed amendments had been passed.

Policies have also been written to address the use of sex-selective abortions. Cultural norms and discriminatory practices that favor males, including sex-selective abortion, have resulted in an imbalance in the sex ratio in India: As of 2014-2016, there were 848 females per 1,000 males at birth. ${ }^{20}$ To ameliorate this imbalance, the government enacted the Pre-Natal Diagnostic Techniques Act in 1994, ${ }^{21}$ amended in 2003 to become the Pre-Conception and PreNatal Diagnostics Techniques (PCPNDT) Act, which prohibits the misuse of prenatal diagnostic tests for the purpose of sex determination. ${ }^{22,23}$ Challenges remain, however, in simultaneously addressing gender-biased sex selection while protecting access to legal abortion services. The Government of India's strict measures to enforce the PCPNDT Act, as well as intense public focus on this issue in recent years, has generated the misperception among women and providers that all abortions are illegal, and has thus led to difficulties in both obtaining and providing safe abortion and postabortion care. ${ }^{24-26}$

In addition, facility-based provision of safe abortion services is hampered, at least in the public sector, by shortages of trained personnel, lack of necessary equipment and frequent transfers of trained providers to unequipped facilities. ${ }^{27}$ The 2012-2013 District Level Household and Facility Survey found that in the country as a whole, $26 \%$ of district hospitals and $77 \%$ of community health centres (CHCs) did not have a gynecologist on staff. ${ }^{28}$ In the private sector, as well, providers lack training opportunities to learn how to perform abortions, and trained providers may not work in facilities that are registered to provide the service. ${ }^{10}$

\section{Sexual and reproductive health and abortion in Gujarat}

Abortion and unintended pregnancy are closely linked to contraceptive use and other indicators of women's status, such as age at marriage, literacy and level of urbanization, all of which may be associated with women's and couples' desire to control the timing of their births and to limit their fertility.

Gujarat is one of the most urbanized and industrialized states of India, and its population is generally considered to be better off, in terms of economic and social indicators, than the population of India as a whole. Of the 17 million women of reproductive age (15-49 years old) in the state in $2015,{ }^{29} 44 \%$ lived in urban areas and $73 \%$ were literate. ${ }^{30}$ As of $2011-2012,17 \%$ of all people residing in the state lived in poverty. ${ }^{31}$

According to data from the 2015-2016 National Family Health Survey (NFHS-4), 43\% of all married women of reproductive age in Gujarat were using a modern contraceptive method, compared with $48 \%$ in India as a whole (Table 1, page 6). ${ }^{30,32}$ This proportion has declined in Gujarat over the past decade, from $57 \%$ in 2005-2006, an unexpected trend. ${ }^{33}$ The majority of married women who practice modern contraception use female sterilization $(78 \%) ;{ }^{30}$ although this method is appropriate for women who want to cease childbearing, it does not address the needs of women seeking to space births.

As contraceptive use has declined, the proportion of women with an unmet need for contraception-married women who are able to become pregnant and want to prevent pregnancy for at least two years but who are not practicing contraception-has increased, from $8 \%$ to $17 \%$ over the same period. ${ }^{30,33}$ The level of unmet need in the state now exceeds that for India as a whole (13\%). ${ }^{32}$ Unwanted fertility in Gujarat was also substantial in 20152016: On average, women in the state wanted 1.5 children but had 2.0-indicating that many women have more children than they want. ${ }^{30}$ Total fertility has decreased from 2.7 in 1998-1999, but the gap between wanted and total fertility has remained stable over time..$^{30,34}$

Data on the timing of marriage show that the median age at first marriage for women aged 20-49 increased over the past decade in Gujarat, from 18 years in 20052006 to roughly 20 years in 2015-2016..$^{30,33}$ It appears that early marriage has decreased slightly in the state: Fourteen percent of women aged 15-19 had ever been married at the time of the 2015-2016 survey, compared with 20\%

\footnotetext{
* In 2010, the MoHFW's Comprehensive Abortion Care Training and Service Delivery Guidelines for providing comprehensive abortion care indicated in a footnote that MMA up to 63 days' gestation is safe. ${ }^{14}$ However, amendments to the MTP Act that would reflect this modification are still awaiting passage in Parliament.
} 
TABLE 1

\section{Trends in contraceptive use and fertility preference indicators from National Family Health Surveys, Gujarat, 1998-1999, 2005-2006 and 2015-2016}

\begin{tabular}{|c|c|c|c|}
\hline Indicator & $\begin{array}{c}1998- \\
1999\end{array}$ & $\begin{array}{c}2005- \\
2006\end{array}$ & $\begin{array}{c}2015- \\
2016\end{array}$ \\
\hline \multicolumn{4}{|c|}{ Contraceptive use among married women 15-49 } \\
\hline$\%$ using any method & 59.0 & 66.6 & 46.9 \\
\hline$\%$ using modern methods & 53.3 & 56.5 & 43.1 \\
\hline$\%$ using traditional methods & 5.6 & 10.1 & 3.8 \\
\hline $\begin{array}{l}\text { Unmet need for contraception } \\
\text { among married women } 15-49\end{array}$ & 8.5 & 8.0 & 17.0 \\
\hline$\%$ with unmet need for spacing & 4.8 & 4.3 & 6.7 \\
\hline$\%$ with unmet need for limiting & 3.7 & 3.7 & 10.3 \\
\hline \multicolumn{4}{|l|}{ Fertility rate among women $15-49$} \\
\hline Wanted & 2.1 & 1.8 & 1.5 \\
\hline Total & 2.7 & 2.4 & 2.0 \\
\hline \multicolumn{4}{|l|}{ Timing of marriage } \\
\hline $\begin{array}{l}\text { Median age at first marriage (in years) } \\
\text { among women } 20-49\end{array}$ & 17.9 & 18.0 & 19.7 \\
\hline \% never married among women 15-19 & 73.5 & 80.3 & 85.8 \\
\hline$\%$ never married among women $20-24$ & 20.9 & 28.0 & 36.1 \\
\hline$\%$ illiterate among women $15-49$ & 38.8 & 35.8 & 27.1 \\
\hline \multicolumn{4}{|l|}{ Residence among women 15-49 } \\
\hline$\%$ urban & 43.5 & 43.3 & 44.4 \\
\hline$\%$ rural & 56.5 & 56.7 & 55.6 \\
\hline
\end{tabular}

NOTE: Proportions presented in the text, figures and tables may differ slightly because of rounding. SOURCES: references 30, 33 and 34.

in 2005-2006. The increase in age at marriage has likely contributed to the decline in the total fertility rate and to trends in related indicators.

An important contributing factor to unintended pregnancy and abortion incidence is the extent to which unmarried young women are sexually active. In the most recent NFHS, fewer than 5\% of unmarried women aged 15-24 reported ever having had sex. ${ }^{30}$ However, studies on this topic are likely to reflect a high level of underreporting, given the strong social sanctions against sexual activity outside of marriage.

Rising literacy is generally associated with an increase in women's role in decision making regarding matters such as contraceptive use, timing of births and family size. The NFHS shows that women in Gujarat made some important gains in literacy over the past decade: The proportion of those aged 15-49 who were illiterate dropped from 36\% in 2005-2006 to 27\% in 2015-2016. .30 $^{30}$ Further analyses are needed to understand the relationship between gains in literacy in the state and sexual and reproductive health behaviors.

A few previous studies have provided estimates of abortion in Gujarat, but each has relied on incomplete sources of data. Data from 2014-2015 on the incidence of abortion in Gujarat, compiled by the MoHFW, showed 25,941 induced abortions occurred in a 12 -month period. ${ }^{1}$ In 2012, a study using two indirect estimation techniques (the Mishra-Dilip method and the Shah Committee's method) placed the state's induced abortion incidence far higher, at 140,000-277,000 per year. ${ }^{35}$

In addition to these studies, community-based surveys of women (such as the NFHS) collect some data on abortion but are not a reliable source for estimating incidence because, in response to the stigma associated with terminating a pregnancy, women typically underreport their abortions in face-to-face interviews, a problem that may be exacerbated if women believe abortion to be illegal. The estimation methodology used in our UPAI study improves on those of previous studies because it does not rely on incomplete official statistics and instead uses direct measurement approaches that are feasible in the current Indian context: survey data from a representative sample of public and private health facilities that provide abortions and national data on sales of MMA (see Survey Methodology, page 8).

Although knowing the number of abortions performed is important because it helps us understand the magnitude of this public health issue (and because it allows for indirect estimation of unintended pregnancy), information on how and where abortion takes place is equally important for policy making and planning. Scant data are available that describe the provision of induced abortion services in Gujarat. Government statistics from 2010 show there were only 1,393 public and registered private facilities approved for provision in the state to serve a population of 16 million women of reproductive age. ${ }^{36,37}$ However, this number is an undercount because it excludes facilities that do not report their services. A few studies have shown that even among facilities approved to provide abortion, many do not offer the services because they lack trained providers. ${ }^{38-40}$ Other studies show that challenges and delays in obtaining certification resulted in abortion 
provision by facilities that were not approved for it; these services, though safe, were deemed illegal. ${ }^{41}$

Few data exist on the methods women in Gujarat use to terminate pregnancies outside of health facilities. However, studies from various parts of the country show these methods range widely in effectiveness and safety. They include MMA, ayurvedic and homeopathic preparations procured from a medicine shop or pharmacist, ${ }^{42,43}$ and home remedies..$^{44,45}$ 
The UPAI study draws in large part on two surveys conducted in 2015 in six Indian states (Assam, Bihar, Gujarat, Madhya Pradesh, Tamil Nadu and Uttar Pradesh): the Health Facilities Survey (HFS), which collected data from 4,001 public and private health care facilities, and the Health Professionals Survey (HPS), which collected data from 552 key informants knowledgeable about abortion in their district or state. * These surveys are described briefly below and in greater detail online (see "supplementary materials" at https://www.thelancet.com/journals/ langlo/article/PIIS2214-109X(17)30453-9). Additional data sources are discussed in the Incidence Methodology on page 21.

\section{Health Facilities Survey}

All public and private medical colleges in the state were surveyed in the HFS, and other types of facilities were selected using the following stratified random sampling strategy. First, approximately $70 \%$ of districts in Gujarat were randomly selected; within these districts, public, private and NGO facilities were identified and sampled. In the public sector, $80 \%$ of district hospitals, $80 \%$ of subdivisional hospitals and $23 \%$ of $\mathrm{CHCs}$ in the selected districts were sampled using lists obtained from the Ministry of Health and Family Welfare. PHCs were identified from among those linked administratively to the selected $\mathrm{CHCs}$; ultimately, $12 \%$ of all PHCs in Gujarat were sampled. In addition, all Employees' State Insurance Corporation hospitals listed on government websites were included.

Because no comprehensive lists of private and NGO facilities exist, an exercise was conducted in a representative sample of urban and rural areas of the state, with the objective of developing a list of all private and NGO facilities (hospitals, nursing and maternity homes, and clinics) that provide or have the capacity to provide abortion-related services (induced abortion, postabortion care or both). The listing exercise also covered certain public facilities for which no comprehensive lists were available: railway hospitals, some Employees' State Insurance Corporation hospitals, military hospitals, municipal hospitals, and urban health centres. In urban areas, the listing exercise was conducted within a sample of urban wards designed to represent towns and cities of all sizes and to cover approximately $7.5 \%$ of Gujarat's total urban population; in rural areas, it was conducted within the catchment areas of a representative sample of $\mathrm{CHCs}$.

The listing exercise reliably captured facilities currently providing abortion-related services; however, it may have unintentionally excluded some private and NGO facilities that were not providing such services at the time but had the capacity to do so. To ensure consistency across states, only data from those private or NGO facilities that reported providing abortion-related services were used in the results presented in this report. Thus, although the public-sector sample and study findings represent all public facilities, the private-sector results represent only the subset of facilities that were providing abortion-related care at the time of the survey, in 2015. As a result, this study does not measure the proportion of private facilities that are capable of offering abortion services but do not do so.

\section{In Gujarat, 18 of 26 districts were} sampled for inclusion in the HFS, and interviews were conducted at 262 public facilities, as well as at 172 private and five NGO facilities that were providing abortion-related services. After applying sample weights, these facilities represent all 1,561 public facilities operating in Gujarat, including 484 public facilities likely to be offering abortion-related care, as well as the 1,811 private and NGO facilities offering such care. Because NGOs made up a very small proportion of our sample, they were combined with private facilities in analyses. We present results differentiating facilities according to public or private ownership and type (which generally corresponds to facility capacity). ${ }^{\dagger}$ Although we attempted to capture registration status with our HFS questionnaire, it is likely that we did not get completely accurate reporting on this potentially sensitive subject, either because unregistered providers of abortion feared admitting they were not registered or because respondents were not aware of what it means to be registered.

HFS data were collected at the facility using face-to-face structured interviews with a senior health care professional knowledgeable about the provision of abortion-related services at his or her facility-typically, the director or head of the facility or of the obstetrics and gynecology department. In some facilities, the HFS was completed by a doctor, nurse, midwife, facility in-charge or other professional knowledgeable about services at that site. The survey collected information on reproductive health and abortionrelated services offered at each facility, including the types of services offered, the number of women who presented for abortion-related care, availability of trained staff, types of postabortion complications treated and facility caseloads.

To qualify for the interview, respondents had to have worked at that facility for at least six months in a capacity in which they would know about the facility's abortion cases. They were asked to estimate the number of induced abortions in the past month and in an average month (to account for seasonality in abortion demand). ${ }^{\ddagger}$ For these numbers, we relied on estimates, rather than official documentation, because facilities often do not maintain complete records of services provided (for a variety of reasons, including lack of registration, desire to avoid cumbersome reporting requirements under the MTP Act and desire to avoid paying taxes on the abortions they provide $\left.{ }^{46}\right)$. We also asked facilities to provide their statistics on abortion from their log books so that we could compare their official reports with their estimated numbers, but not all facilities did so. Therefore, we 
rely on the estimated numbers from the respondents. In addition to gathering data from health facilities, we also gathered data on abortion provision from the administrative records from all large NGO networks. ${ }^{\S}$

\section{Health Professionals Survey}

Data for the HPS were collected using face-to-face interviews with a sample of key informants selected from approximately $50 \%$ of the districts in each state. Informants were purposively selected based on their knowledge of and exposure to abortion and women's health issues. Most (81\%) were health care providers, including allopathic doctors and nurses, providers from other systems of medicine and pharmacists; the remaining one-fifth were other knowledgeable professionals, such as health administrators, academicians, activists, policymakers, lawyers and journalists. Informants were drawn from both the public and private sectors and from both rural and urban areas. The HPS collected information on informants' perceptions of the conditions under which induced abortion services and postabortion care are obtained in their district or state, including the types of providers offering services, the types of abortion methods used, types and severity of complications, access to treatment, and variations in the conditions of abortion provision according to women's socioeconomic status and rural or urban location. In Gujarat, 79 key informants were interviewed.

\section{Footnotes}

*Throughout this report, the text and figures show proportions as whole rounded numbers, while the tables show them rounded to one decimal place. Thus, there are occasional slight discrepancies between text, figures and tables (for example, the original value 46.47 would appear as 46 in the text but 46.5 in the tables).

†Public facilities were grouped into hospitals (including rural, district/civil, sub-divisional, municipal, tertiary, railway, Employees' State Insurance Corporation and refinery hospitals, and public medical colleges), CHCs (including first referral units and non-first referral units), PHCs (including those that are and are not open 24-7, and block PHCs) and urban public facilities (urban health centres). Private facilities were grouped into hospitals (including multispecialty hospitals, specialized hospitals and private medical colleges), nursing and maternity homes, and clinics.

$\neq$ We first converted the data to annual caseloads, multiplying caseloads that were reported for the past and average month by 12 , and combining these with responses reported for the past and average year. We then took the average of the number of induced abortions reported in the past and average year as the best estimate of the total annual number of pregnancies terminated in each facility. By applying sample weights, we obtained total estimates at the state level, by type of facility and ownership.

$\S A$ few NGOs were included in the HFS private facility sample. We cross-checked these with the compiled list of NGOs to ensure there were no duplicates. 


\section{Provision of Abortion-Related Services}

W omen's access to safe, legal abortionrelated services depends to a large extent on whether nearby facilities provide such care and what specific types of services are available. These topics are discussed below, and additional details are available in the fact sheet, "Provision of abortion and postabortion services in Gujarat, 2015." 47

In 2015, an estimated 2,294 facilities in Gujarat were providing any abortion-related services (induced abortion, postabortion care ${ }^{\dagger}$ or both types of services); 484 facilities (21\%) were public and 1,811 (79\%) were private (Table 2 ). Although $50 \%$ of facilities reported offering both induced abortion and postabortion care, $11 \%$ restricted their services to the former, and $39 \%$ to the latter. The majority of public hospitals (76\%) offered both abortion and postabortion care, whereas more than half of $\mathrm{CHCs}(51 \%)$ and PHCs $(56 \%)$ offered only postabortion care. Overall, $89 \%$ of facilities

†Unless otherwise specified, the term postabortion care refers to care related to complications of both abortion and miscarriage. providing any abortion-related services offered postabortion care and $61 \%$ offered induced abortion.

Sixty-nine percent of facilities offering abortion-related services in Gujarat were located in urban areas, where a somewhat disproportionate $44 \%$ of the state's female population resides. ${ }^{30}$ Among facilities that offered such services, only $3 \%$ of public hospitals and $18 \%$ of private hospitals-the facilities best equipped to handle severe complications or later-term abortions-were located in rural areas. Among facilities offering any abortion-related care, $50 \%$ in rural areas were private, compared with $92 \%$ in urban areas (Appendix Table 1).

Among the estimated 1,561 public facilities in Gujarat, only $31 \%$ reported offering induced abortion, postabortion care or both services, whereas $69 \%$ offered neither service (Figure 1, page 11). The proportion providing these services varied widely by provider type: Some $91 \%$ of public hospitals, $52 \%$ of $\mathrm{CHCs}$ and $20 \%$ of PHCs provided any abortion-related care in 2015. We cannot give this breakdown for private facilities because our list included mainly

TABLE 2

\section{Number and percentage distributions of facilities offering induced abortion, postabortion care or both, by services offered and location, Gujarat, 2015}

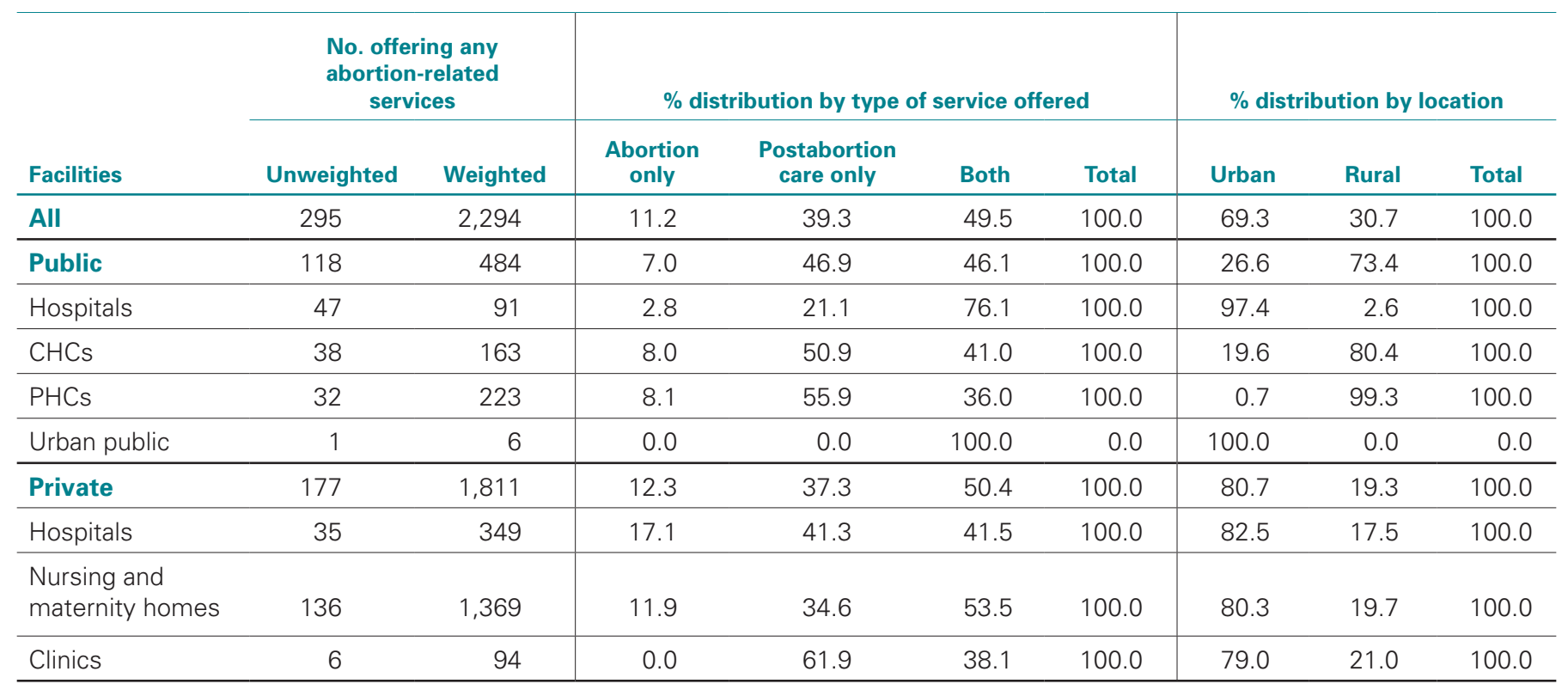

NOTES: Postabortion care refers to care for complications resulting from either induced abortion or miscarriage. $\mathrm{CHC}=\mathrm{Community} \mathrm{health} \mathrm{centre.}$ $\mathrm{PHC}=$ primary health centre. Proportions presented in the text, figures and tables may differ slightly because of rounding. SOURCE: Health Facilities Survey. 
those providing abortion-related care.

Among all public and private facilities that offered induced abortion services in 2015, 76\% offered both MMA and surgical methods, $12 \%$ offered only MMA, and $12 \%$ offered only surgical methods (Appendix Table 2). A higher proportion of private facilities (80\%) than public facilities (59\%) offered both types of methods.

\section{Facilities not offering induced abortion}

Among facilities whose abortion-related services were restricted to postabortion care, the reasons reported for not offering induced abortion varied according to public or private ownership. Public facilities offering only postabortion care commonly cited lack of trained staff (77\%) and lack of equipment or supplies (44\%) as reasons for not offering induced abortion (not shown). In contrast, private

FIGURE 1

PUBLIC PROVISION

\section{Only $31 \%$ of all public facilities in Gujarat} offer any abortion-related services.

$\%$ of all public facilities, 2015

100

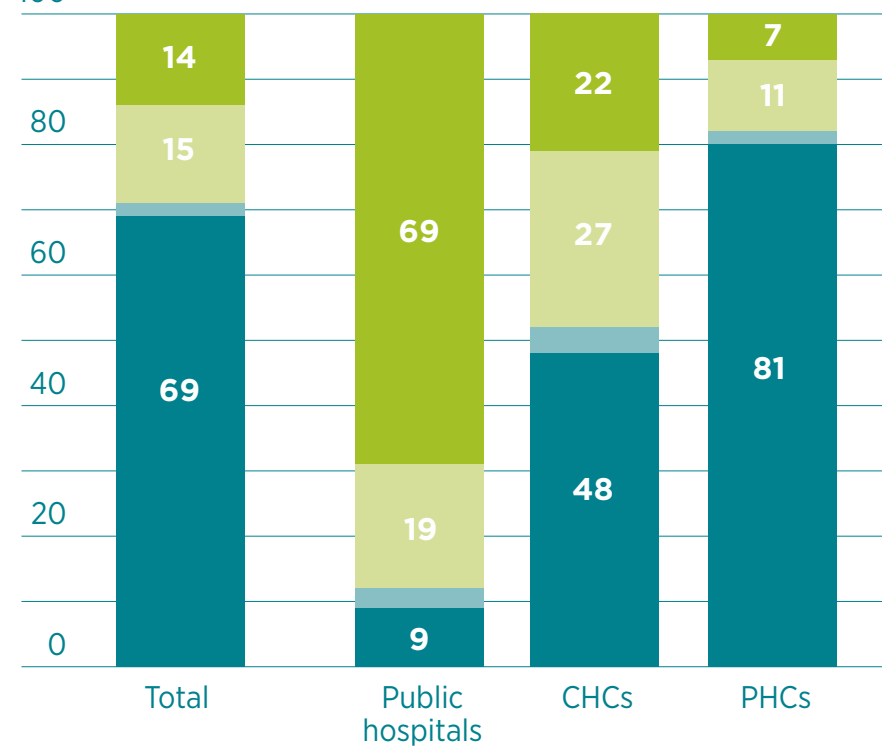

Induced abortion and postabortion care

Postabortion care only

Induced abortion only

No abortion-related services

NOTES: $\mathrm{CHC}=$ community health centre. $\mathrm{PHC}=$ primary health centre. Because of rounding, proportions may not add to 100 and may differ slightly from those in the text and tables. SOURCE: Health Facilities Survey. facilities offering only postabortion care most commonly reported religious or social reasons (48\%) or lack of registration to provide abortion (42\%); few reported lack of trained staff $(11 \%)$ or lack of equipment or supplies (11\%).

\section{Availability of postabortion care}

Because medical complications can occur at any time of day or night, an important indicator of access to postabortion care is whether a facility is open 24 hours a day, seven days a week. In Gujarat, among facilities providing postabortion care services in 2015, 85\% (including more than $85 \%$ of public hospitals, CHCs, private hospitals, and nursing and maternity homes) offered care 24-7 (Appendix Table 3). Three-fourths of public facilities (74\%) providing postabortion care offered it around the clock, compared with $89 \%$ of such private facilities. Availability of 24-7 postabortion care was greater among facilities offering these services in urban areas (90\%) than in rural areas (76\%). 


\section{Induced Abortion Services Provided in Facilities}

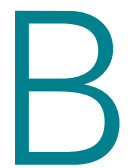

y gathering data from a sample of health facilities providing abortion, we were able to estimate the total number of facility-based abortions provided in Gujarat in 2015. Knowing what methods facilities use is an important part of understanding the abortion landscape, as nearly all surgical abortions-as well as a portion of those using MMA-are provided at facilities.

An estimated 120,800 induced abortions were provided in health facilities in Gujarat in 2015 (Figure 2 and Appendix Table 4). This estimate was derived by summing the weighted number of abortions provided by each facility type that year. (Abortions performed outside of health facilities are discussed later in this report.) The small share provided by NGOs are not included here because we obtained those data from administrative sources and not through our facility-based survey; therefore, we have less detail on those abortions. Only $19 \%$ of all facility-based abortions occurred in the public sector: Two-thirds (68\%) of these were provided in hospitals, $14 \%$ in $\mathrm{CHCs}, 13 \%$ in $\mathrm{PHCs}$ and $6 \%$ in other urban public facilities. The large

\section{FIGURE 2}

SETTINGS OF ABORTION PROVISION

\section{Fewer than one-fifth of women obtaining a facility-based abortion go to a public facility.}

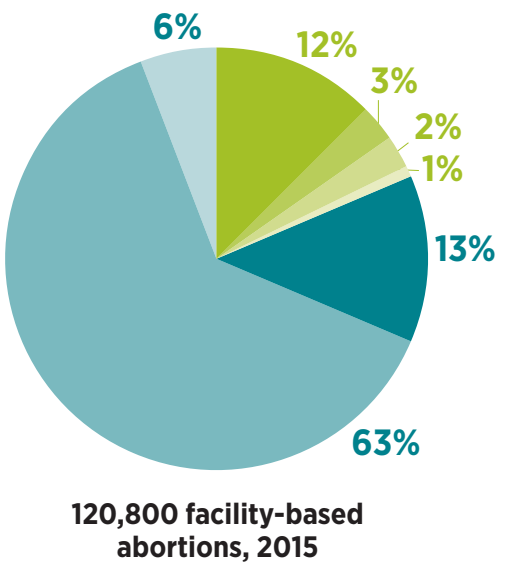

Public hospitals

$\mathrm{CHCS}$

PHCS

Urban public facilities

Private hospitals

Nursing and

maternity homes

Clinics

NOTES: $\mathrm{CHC}=$ community health centre. $\mathrm{PHC}=$ primary health centre. Total excludes abortions provided by some NGOs. Proportions presented in the text, figures and tables may differ slightly because of rounding. SOURCE: Health Facilities Survey. majority-81\%—of facility-based induced abortions in 2015 took place in the private sector. Of these, $77 \%$ were provided in nursing and maternity homes, $16 \%$ in hospitals and $7 \%$ in clinics.

On average, each public hospital provided about 210 induced abortions in 2015; CHCs provided 40, PHCs provided 30 and other urban public facilities provided 200. Private hospitals had a caseload of about 70 abortions and private nursing and maternity homes each provided around 80 , while clinics had higher average caseloads of 200 abortions.

Eleven percent of induced abortions provided in privatesector facilities in Gujarat-9\% of all facility-based abortions in the state-were performed in facilities that HFS respondents reported as not being registered to offer that service. Of these, $90 \%$ took place in unregistered nursing and maternity homes.

\section{Timing of abortion and facilities' gestational limits}

Nearly all (96\%) of the facility-based induced abortions taking place in Gujarat in 2015 were performed in the first trimester (i.e., the first 12 weeks of gestation): $68 \%$ in the first seven weeks and $28 \%$ in weeks 8-12 (Appendix Table 5). Only $4 \%$ of facility-based abortions occurred beyond 12 weeks.

At most types of public and private facilities, 95-100\% of induced abortions occurred in the first trimester. At $\mathrm{CHCs}, \mathrm{PHCs}$, urban public facilities and private clinics, all were performed in the first trimester. At public hospitals, the proportion of abortions taking place in the second trimester (13-22 weeks' gestation; 11\%) was somewhat higher than in other types of facilities.

Although abortion is legally permitted up to 20 weeks' gestation in facilities approved for second-trimester abortion, many set earlier gestational limits. Among facilities offering abortion in Gujarat, 78\% reported offering terminations in the first trimester only, including 100\% of $\mathrm{CHCs}$, about two-thirds of public hospitals $(62 \%)$, and three-fourths of private hospitals $(72 \%)$ and private nursing homes and maternity hospitals (78\%; Figure 3, page 13$).^{\ddagger}$ Across facilities, the proportion offering abortion services

\#Data based on responses to a question about facility capacity, not on actual cases. 


\section{GESTATIONAL LIMITS}

The large majority of facilities providing abortion restrict provision to the first trimester of pregnancy.

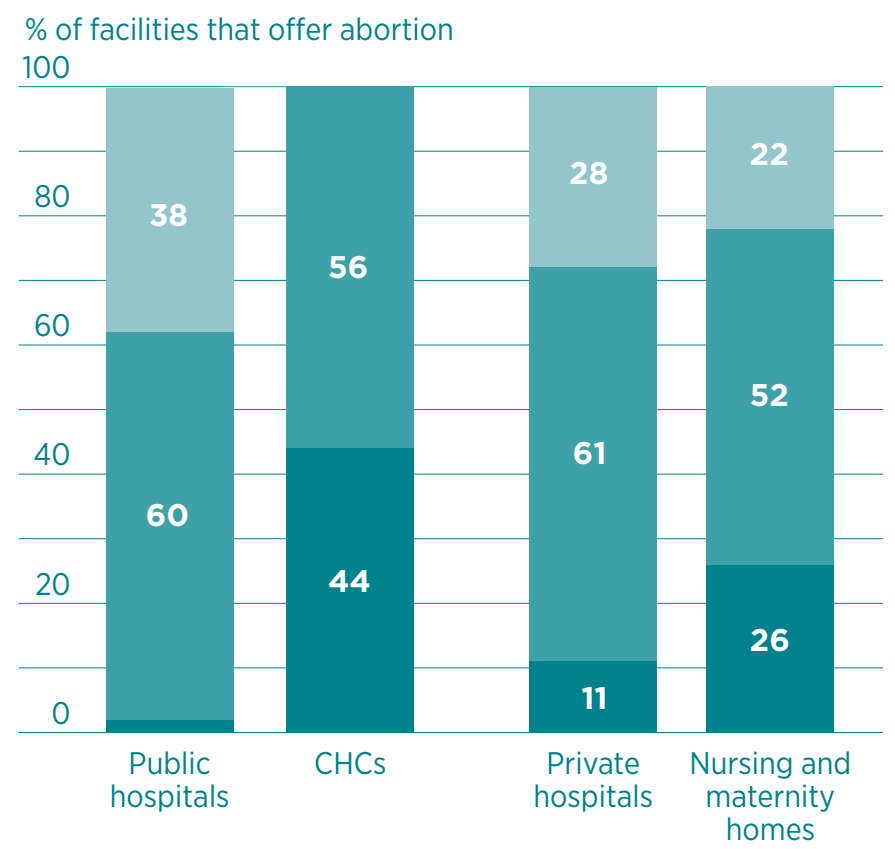

Maximum gestation at which abortion is offered

— $<8$ weeks 8-12 weeks__ >12 weeks

NOTES: The first trimester is weeks $0-12$. $\mathrm{CHC}=$ community health centres. Because of rounding, proportions may not add to 100 and may differ slightly from those in the text and tables. SOURCE: Health Facilities Survey.

beyond that gestation was highest among public hospitals.

Among facilities offering abortion only in the first trimester, the most commonly cited reasons for not offering second-trimester terminations were lack of registration to provide abortion at that gestation (32\%), lack of trained staff or providers $(26 \%)$ and fear of providing sex-selective abortions (26\%; not shown). Facilities also cited lack of equipment or supplies (15\%), religious or social concerns of administrators or providers (13\%) and lack of blood storage facilities (12\%). The proportions reporting reasons related to sex selection, registration, and religious or social concerns were higher among private facilities than among public facilities, while the proportions lacking trained providers, blood storage facilities, and equipment and supplies were higher among public sites. Inadequate infrastructure was cited by $19 \%$ of public facilities not offering secondtrimester abortions but by only $2 \%$ of corresponding private facilities. Larger proportions of lower-level facilities (CHCs, PHCs and private clinics) than of higher-level facilities cited lack of equipment or supplies as a reason for not providing terminations in the second trimester.

\section{Abortion methods used in facilities}

Among facilities that provide abortion in Gujarat, the majority $(76 \%)$ offered both MMA and surgical procedures. However, facilities offering abortion often reported using methods that are not in line with best practices. World Health Organization (WHO) guidelines recommend the use of MMA or vacuum aspiration for most abortions; dilatation and evacuation (D\&E) is recommended in situations in which the other methods are contraindicated (typically in the second trimester), and dilatation and curettage (D\&C) is no longer recommended as an abortion method at any gestation..$^{48}$

Among abortions occurring in health facilities in Gujarat, $41 \%$ were performed using MMA (Figure 4). The proportion using MMA was higher in private facilities $(44 \%)$ than

FIGURE 4

\section{ABORTION METHODS}

\section{More than half of women in Gujarat who obtain a facility-based abortion have a surgical procedure.}

$\%$ of women who obtain a facility-based abortion 100

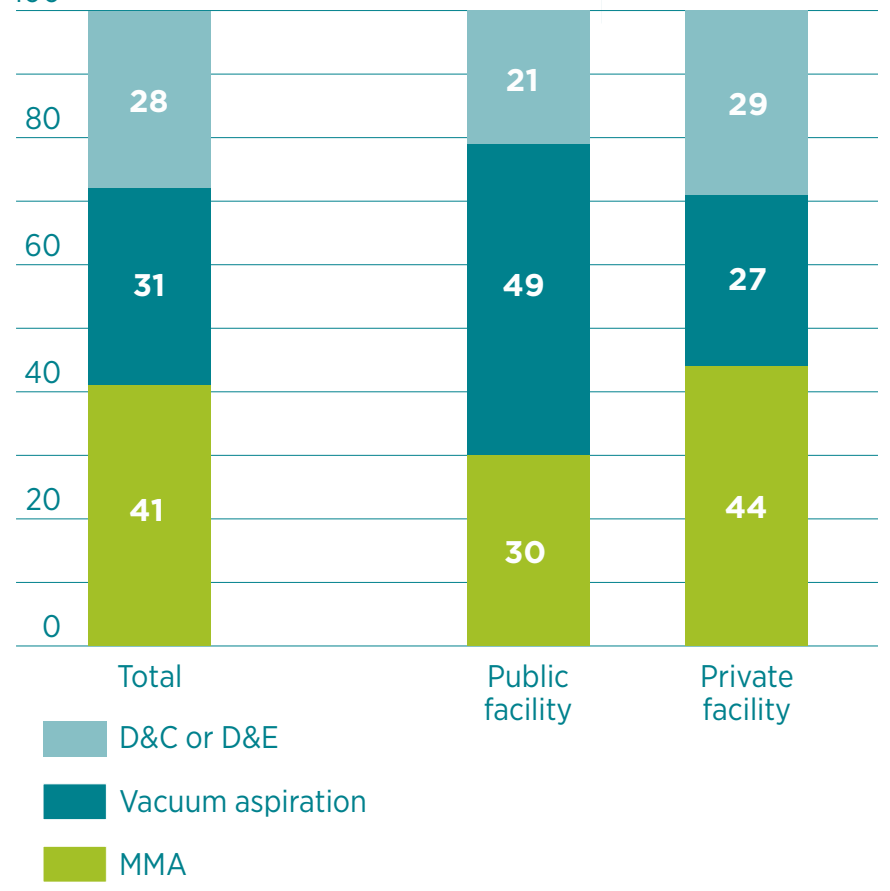

NOTES: $M M A=$ medical methods of abortion. $D \& C=$ dilatation and curettage. $\mathrm{D} \& \mathrm{E}=$ dilatation and evacuation. Because of rounding, proportions may not add to 100 and may differ slightly from those in the text and tables. SOURCE: Health Facilities Survey. 
in public facilities (30\%). MMA was particularly uncommon in public hospitals, where the large majority of abortions $(81 \%)$ were done using surgical methods (Appendix Table 6). Thirty-one percent of facility-based abortions were performed with either manual or electric vacuum aspiration (MVA or EVA), which are the least invasive surgical methods, and $28 \%$ involved more invasive surgical procedures: $D \& C$ or D\&E. We have grouped these latter two methods together because providers may use $D \& C$ as a generic term for surgical abortion; therefore, individual proportions may not be reliable. ${ }^{\S 49}$

The share of procedures performed using $D \& C$ or $D \& E$ varied little according to whether facilities were public $(21 \%)$ or private $(29 \%)$. These methods together were more commonly used than vacuum aspiration at private nursing and maternity homes, regardless of registration status. Vacuum aspiration was more commonly used than D\&C or D\&E at all other types of facilities, including PHCs and private clinics, which is important because these relatively low-level facilities are the least likely to be equipped to be able to safely provide more invasive surgical procedures. Given that only about $4 \%$ of facility-based abortions occurred after the first trimester, we can infer that, on the whole, providers in Gujarat are relying on more invasive and riskier abortion techniques than they should be at early gestations.

\section{Barriers to seeking safe abortion services}

When asked what barriers women face when seeking safe abortions, HFS respondents reported fear of stigma $(60 \%)$ and objections from a family member (47\%; not shown). Other barriers included cost to women (16\%) and lack of information on safe services (15\%). About one in five respondents (19\%) felt that women face at least three barriers to obtaining a safe abortion. Respondents from public and private facilities generally had similar perceptions of the barriers women face.

Women seeking abortions at health facilities may encounter a different set of barriers, and these are typically related to the facility or staff being unable or unwilling to provide the abortion under some circumstances. In Gujarat, $56 \%$ of facilities that provide abortion reported turning away at least one woman seeking a termination in the year preceding the survey; among this group of facilities, 57\% cited capacity-related reasons (provider not available, MMA not available or facility gestational limits exceeded; not shown). In addition, staff at health

§Providers reported $16 \%$ of women obtaining facility-based abortions underwent D\&C and $12 \%$ underwent D\&E. facilities providing abortion services either may not be well informed about the conditions under which termination is legally permitted or may have social or personal reasons for choosing not to offer it to some women. For example, among the facilities that reported having turned away at least one woman seeking an abortion, $18 \%$ had done so because the women did not obtain consent from a partner or other family member, and $37 \%$ had done so because women were unmarried or had no children, or because the provider considered them to be too young. Twenty-two percent of facilities that turned away women cited reasons related to sex selection. 


\section{Provision of Postabortion Care}

W hen induced by prescription drug or performed surgically by a trained provider under hygienic conditions, abortion is very safe. However, because abortions occur

in a variety of settings in Gujarat-including at registered and unregistered health facilities, as well as outside of the health care system - the safety of the method used and the incidence of complications vary. In the HPS, key informants said that, particularly in rural areas, some women resort to methods such as herbal solutions, homeopathic medication, abdominal massage or pressure, and insertion of solid or sharp objects into the vagina, cervix or uterus.

It is important to assess the extent to which unsafe abortions are occurring, as well as the incidence of complications, but doing so is difficult because unsafe abortion is often clandestine and is not captured in official reporting. Representative estimates from the HFS of the amount of complication-related care provided by health facilities offer a good indicator of the incidence of unsafe abortion, although it is an underestimate because it excludes women who need facility-based care and do not receive it. This underestimate is partly offset because some women or providers may misdiagnose bleeding, which is part of the normal process after a medication abortion, as an abortion complication. These women are included in providers' reports as having had a complication, although their abortion likely would have been completed safely without the additional medical care.

According to 2015 HFS data, about 105,900 women in Gujarat were treated for complications that resulted from either induced abortion or miscarriage (Table 3); this care took place in the estimated 2,038 public and private facilities providing postabortion care in the state. Of these women, we estimated that 67,100 were treated for complications resulting from abortion, and 38,800 were treated for complications related to miscarriage

TABLE 3 (discussed in greater detail on page 17). Among all patients treated for complications, $19 \%$ obtained treatment in public facilities, while the remaining $81 \%$ went to private facilities.

On average, each facility providing postabortion care treated 50 women for complications of induced abortion and miscarriage in 2015, and this average was about the same at private and public facilities. Among public facilities, hospitals treated the highest number of cases (110). Private nursing and maternity homes accounted for the largest proportion of postabortion care services: Some $61 \%$ of patients, or 65,000 , got care in these facilities in Gujarat in 2015.

\section{Types of complications treated}

The types of medical problems women presented with help us understand how severe their complications were and what interventions and medical resources they may have needed. Knowing women's diagnosis on admission

\section{Annual number of women treated for complications of induced abortion or miscarriage and selected measures of provision of care, Gujarat, 2015}

\begin{tabular}{|c|c|c|c|c|c|}
\hline \multirow[b]{2}{*}{ Facilities } & \multirow[b]{2}{*}{$\begin{array}{l}\text { Annual } \\
\text { no. of } \\
\text { cases }\end{array}$} & \multicolumn{4}{|c|}{ Facilities offering care for complications } \\
\hline & & No. & $\begin{array}{c}\text { Average } \\
\text { annual no. } \\
\text { of cases } \\
\text { per facility }\end{array}$ & $\begin{array}{c}\% \text { distribution } \\
\text { of cases } \\
\text { by facility } \\
\text { ownership }\end{array}$ & $\begin{array}{c}\% \text { distribution } \\
\text { of cases } \\
\text { by facility } \\
\text { type }\end{array}$ \\
\hline All & 105,900 & 2,038 & 50 & 100.0 & 100.0 \\
\hline Public & 20,300 & 450 & 50 & 100.0 & 19.1 \\
\hline Hospitals & 10,000 & 89 & 110 & 49.3 & 9.4 \\
\hline $\mathrm{CHCs}$ & 6,300 & 150 & 40 & 30.9 & 5.9 \\
\hline $\mathrm{PHCs}$ & 3,500 & 205 & 20 & 17.3 & 3.3 \\
\hline Urban public & 500 & 6 & 80 & 2.5 & 0.5 \\
\hline Private & 85,600 & 1,588 & 50 & 100.0 & 80.9 \\
\hline Hospitals & 15,800 & 289 & 50 & 18.4 & 14.9 \\
\hline $\begin{array}{l}\text { Nursing and } \\
\text { maternity homes }\end{array}$ & 65,000 & 1,205 & 50 & 75.9 & 61.4 \\
\hline Clinics & 4,900 & 94 & 50 & 5.7 & 4.6 \\
\hline
\end{tabular}

NOTES: $\mathrm{CHC}=$ community health centre. $\mathrm{PHC}=$ primary health centre. Numbers may not add to totals because of rounding. Proportions presented in the text, figures and tables may differ slightly because of rounding. SOURCE: Health Facilities Survey. 
also helps to assess the extent to which women actually needed treatment, given the high overall level of MMA use (discussed later in this report) and the potential for normal bleeding to be misdiagnosed as a complication.

Survey respondents were asked to estimate the proportion of women with each of the major types of complications, among all women treated for complications related to either induced abortion or miscarriage in their facility. Because women may experience more than one type of complication, multiple responses were permitted. In Gujarat, incomplete abortion resulting from MMA was the most commonly reported complication, and HFS respondents estimated that it affected $48 \%$ of women obtaining care for complications (Figure 5 and Appendix Table 7). Prolonged or abnormal bleeding was the second most commonly reported complication type $(31 \%)$. The third most common diagnosis among these patients was incomplete abortion from methods other than MMA (22\%), which can result from either abortion or miscarriage.

Treatment for incomplete abortion resulting from MMA and prolonged bleeding are likely to be highly overlapping categories, and estimates of the proportion of women treated for these types of complications likely included many cases in which abortions would have been safely completed without need for further intervention, had women been given the correct information and counseling. An unknown proportion of women received needed treatment for incomplete abortion because of incorrect use of this method, but it is likely this proportion was small, given that MMA using a combination of misoprostol and mifepristone, when administered correctly and within a nine-week gestational limit, is $95-98 \%$ effective. ${ }^{50}$

Relatively small proportions of women were estimated to have been treated for severe complications, such as infection of the uterus and surrounding areas, sepsis, shock or physical injuries (e.g., perforation or lacerations) all of which were assumed to have resulted from induced abortion. However, these small proportions represent thousands of women in Gujarat experiencing these severe complications each year. For example, among women treated for complications of induced abortion, an estimated $9 \%$ of patients-6,000 women-received care for infection of the uterus or surrounding areas (the most commonly treated severe complication) in 2015. Four percent of patients treated for abortion complications received treatment for sepsis, 3\% for physical injury and 3\% for shock. It is not possible to estimate precisely how many

FIGURE 5

\section{COMPLICATIONS OF ABORTION AND MISCARRIAGE}

\section{Among women seeking care for complications at facilities, about half present with incomplete abortion after using MMA.}

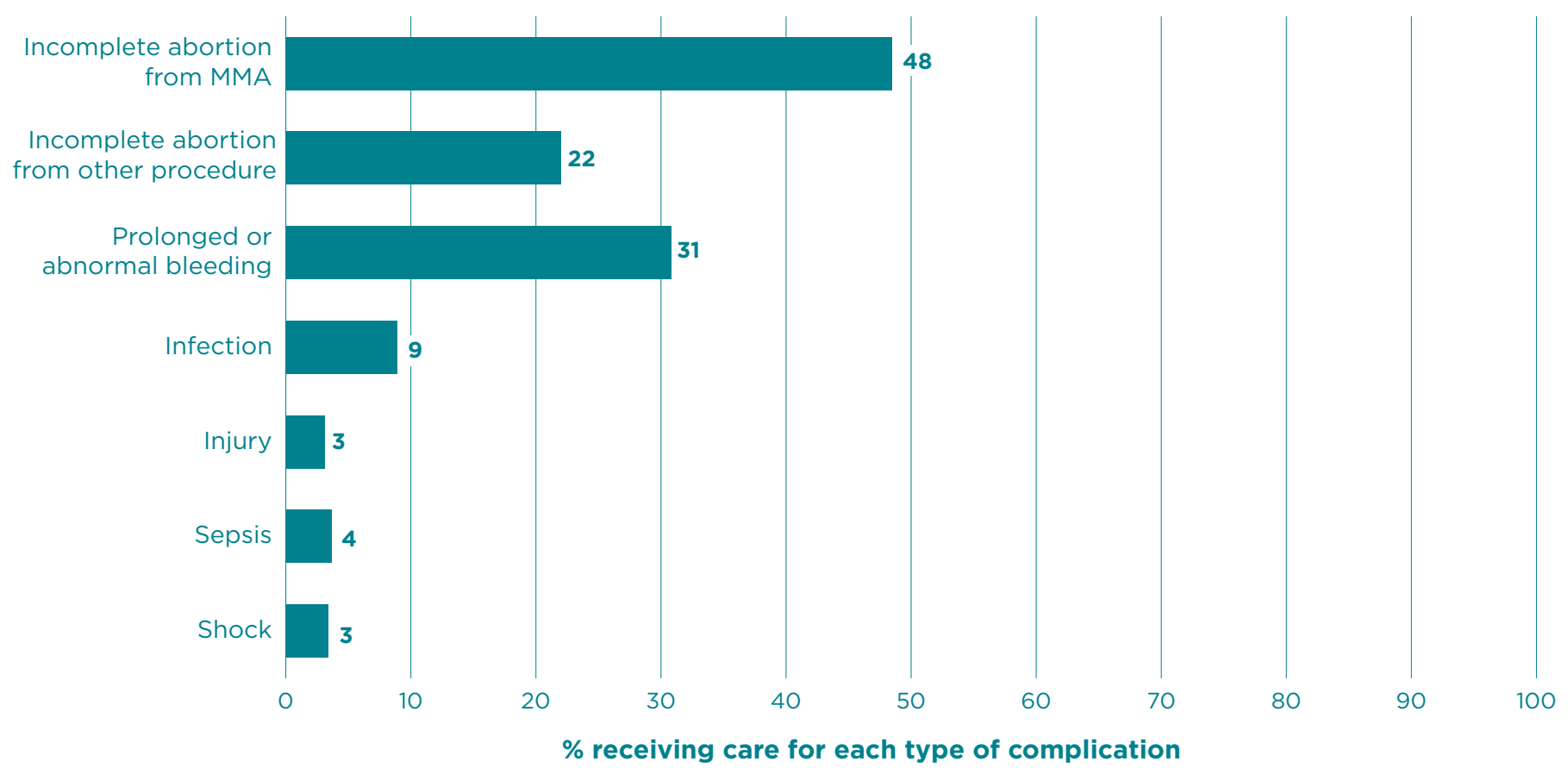

NOTES: Some women experienced more than one type of complication. MMA=medical methods of abortion. Proportions presented in the text, figures and tables may differ slightly because of rounding. SOURCE: Health Facilities Survey. 
women were treated for severe complications overall, as there is some overlap among the categories. The majority of these severe cases likely originated among the group of women having nonfacility abortions using methods other than MMA.

\section{Number of women treated for postabortion complications}

By applying an indirect approach to estimating the number of women who were treated in health facilities for laterterm miscarriages, ${ }^{*}{ }^{*}$ we were able to estimate the number treated specifically for complications of induced abortion. Approximately 67,100 women were treated for induced abortion complications in health facilities in Gujarat in 2015 (Table 4). This means that $8 \%$ of all women terminating pregnancies were treated in health facilities for complications, equivalent to an annual rate of 3.9 women treated per 1,000 women aged 15-49. The induced abortion complication treatment rate in Gujarat is lower than rates found in other South Asian countries with available data: Bangladesh (6.1 per 1,000 in 2014) ${ }^{6}$, Nepal (8.2 in 2014) ${ }^{8}$ and Pakistan (13.9 in 2012). ${ }^{7}$ Among these four countries, abortion is most restricted in Pakistan, which may contribute to that country's higher complication treatment rate. However, it is important to note that the treatment rate does not necessarily directly correspond to abortion safety.
Depending on the context, low treatment rates could represent either low complication rates or insufficient access to postabortion care.

As mentioned previously, estimates may include some cases in which normal bleeding associated with MMA was misidentified as a complication. If all cases of postabortion care to treat MMA-related incomplete abortion are assumed to be cases in which the abortion would have gone to completion without further intervention, the treatment rate for induced abortion complications that truly needed facility-based care would be 0.9 per 1,000 women annually, a total of 15,800 women. This rate is purely hypothetical but helps to express the lower limits of the complication rate. The true rate of induced abortion complications requiring treatment is likely to be higher than this hypothetical rate but lower than the overall estimate of 3.9 cases per 1,000 women aged 15-49.

\footnotetext{
**From clinical studies, we know the proportion of miscarriages that are not fetal losses but that occur in the second trimester (i.e., at 13-22 weeks' gestation). Given that women experiencing these types of miscarriages need care, but not all of them are able to get it (and are therefore not captured in the HFS), we estimate that the probability of getting care for a second-trimester miscarriage is equal to the probability of delivering in a facility. The resulting estimated number of women seeking care for complications related to lateterm miscarriages was then subtracted from the total number of women seeking care for complications.
}

TABLE 4

\begin{tabular}{|c|c|c|c|c|}
\hline \multirow[b]{2}{*}{ Complications treated } & \multicolumn{2}{|c|}{$\begin{array}{l}\text { Weighted no. of women treated } \\
\text { for complications of: }\end{array}$} & \multicolumn{2}{|c|}{$\begin{array}{l}\text { Among women who had an } \\
\text { induced abortion }\end{array}$} \\
\hline & $\begin{array}{c}\text { Abortion and } \\
\text { miscarriage }\end{array}$ & Abortion only & $\begin{array}{l}\% \text { treated for } \\
\text { complications }\end{array}$ & $\begin{array}{l}\text { Treatment rate } \\
\text { (cases per } 1,000 \text { women } \\
\text { aged } 15-49 \text { ) }\end{array}$ \\
\hline Related to MMA & 51,300 & 51,300 & 6 & 3.0 \\
\hline Not related to MMA (minimum estimate) & 54,600 & 15,800 & 2 & 0.9 \\
\hline
\end{tabular}

NOTES: MMA=medical methods of abortion. MMA-related complications are based on Health Facilities Survey respondents' estimates of the proportion of all complications cases treated in their facility that were due to incomplete abortion from MMA. Estimates of complications not related to MMA are the total number of patients treated for complications of abortion or miscarriage minus those treated for MMA-related complications. The number of induced abortion complications not related to MMA $(15,800)$ serves as a best estimate of the number of patients who had induced abortion complications that truly needed treatment (in many cases, women treated for symptoms of incomplete MMA may not have needed treatment in a facility). Numbers may not add to totals because of rounding. Proportions presented in the text, figures and tables may differ slightly because of rounding. SOURCES: Health Facilities Survey and indirect calculations. 


\section{Incidence of Induced Abortion and Unintended Pregnancy}

A bortion incidence is an important indicator of women's need for safe termination services, and it sheds light on women's contraceptive behavior and their experience of unintended pregnancy. The UPAI study provides a comprehensive estimate that reflects the full range of methods and providers that women use in Gujarat. In addition to estimating publicand private-sector abortion provision in health facilities, it estimates abortions in the informal sector, capturing those undertaken via MMA provided by chemists and informal vendors, those performed by untrained providers and

* + These estimates for facility-based abortions differ slightly from those cited earlier in the report because these include official statistics from NGO facilities in addition to public and private facility estimates derived from the HFS. those induced by women on their own (see Incidence Methodology, page 21). Our estimation methodology relies on health sector information whenever possible to avoid the high level of stigma-related underreporting that generally occurs in household surveys that directly ask women about their abortions. ${ }^{51,52}$ More detailed information on our estimation methodology is available online (see "supplementary materials" at https://www.thelancet.com/journals/ langlo/article/PIIS2214-109X(17)30453-9).

\section{Abortion incidence}

We estimated the number of induced abortions in Gujarat in 2015 to be 811,800 and the abortion rate to be 48 abortions per 1,000 women of reproductive age (Table 5). The rate for Gujarat is similar to the rate the UPAI study estimated for Bihar (49), ${ }^{53}$ higher than that for Tamil Nadu (33), ${ }^{54}$ and lower than those for Madhya Pradesh (57), ${ }^{55}$ Uttar Pradesh $(61)^{56}$ and Assam (66). ${ }^{57}$

In Gujarat, roughly 122,000 induced abortions in 2015-15\% of abortions in the state-took place in facilities. ${ }^{* \dagger}$ As stated previously, about 59\% were performed using surgical methods and $41 \%$ using MMA. The majority of facility-based abortions took place in private facilities $(98,300$, or $81 \%)$, some in public facilities $(18 \%)$ and few in NGO facilities $(1 \%)$; both surgical and medical abortions followed a similar distribution by facility type.

MMA obtained outside of the formal health system accounted for an estimated 647,900 induced abortions-80\% of all induced abortions in Gujarat in 2015-and they occurred at a rate of 38 per 1,000 women of reproductive age. These MMA users purchased the drugs directly from chemists or other informal vendors, either without a prescription or with a

NOTES: The number of women aged 15-49 in 2015 is based on projections of the rate of growth between the 2001 and the 2011 population censuses. na=not applicable. Surgical abortion=dilatation and curettage, dilatation and evacuation, and vacuum aspiration. MMA=medica methods of abortion. Numbers may not add to totals because of rounding. Proportions presented in the text, figures and tables may differ slightly because of rounding. SOURCE: See Incidence Methodology. 
prescription from a private physician who did not work at a facility covered by the HFS.

Another 41,900 abortions in 2015 were not performed in facilities and did not use MMA. These procedures, which represent $5 \%$ of all induced abortions in Gujarat, likely encompass the most unsafe methods performed by quacks and other untrained providers and by pregnant women themselves. They may also include some surgical abortions performed by trained professionals outside of the facilities covered by the HFS.

\section{Characteristics of women having an abortion}

Because the HFS was not designed to capture information on the characteristics of women having abortions, we rely on 2015-2016 survey data from the NFHS-4 to ascertain the profile of this group. Among the 4,257 women aged 15-49 in Gujarat who reported that their last pregnancy was in the three years before the survey, only 109 reported that that pregnancy ended in abortion (data not shown). ${ }^{30}$ This translates into an implausibly low $2.6 \%$ of all pregnancies terminated and a rate of only 3.7 abortions per 1,000 women each year. As noted previously, these data are problematic because women tend to underreport their abortions when interviewed. In addition, pregnancy data in the NFHS-4 is almost exclusively for married women, in part due to stigma surrounding sexual activity among unmarried women. Given the apparent high level of underreporting, women who report having an abortion may not accurately represent all women having abortions. Nevertheless, we do not have reason to believe that some women are more likely than others to underreport abortion, so household survey data remain a useful source of information on the demographic and socioeconomic characteristics of the small group of women who reported having had an abortion in this survey.

Among women in Gujarat who reported having had an abortion in the past three years, 58\% lived in urban areas (Appendix Table 8). ${ }^{30}$ Thirty-eight percent were categorized as belonging to the socioeconomically disadvantaged castes collectively designated Other Backward Class, a proportion that reflects the distribution of Gujarat's general population by caste.

Three-fourths of women who reported having had an abortion were already mothers. Thirty percent had one child, one-fourth had two

TABLE 6
FIGURE 6

PREGNANCY INTENTION STATUS

Slightly fewer than half of pregnancies in Gujarat are intended.

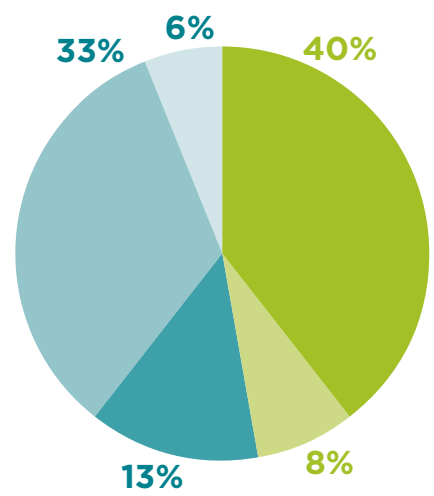

\author{
Intended pregnancies \\ Planned births \\ Miscarriages
}

Unintended pregnancies

Unplanned births

Abortions

Miscarriages

\section{4 million pregnancies, 2015}

NOTE: Proportions presented in the text, figures and tables may differ slightly because of rounding. SOURCE: See Incidence Methodology.

children and one-fourth had three or more. Thirty-nine percent of women who had had an abortion had been married for five years or less; $50 \%$ had been married for $6-15$ years, and $11 \%$ for 16 years or more. By age-group, the greatest proportion of women having an abortion were 25-29 years old (37\%).

Among women who reported having had an abortion, the majority had some schooling: Forty-three percent had 6-11 years of schooling, $22 \%$ had 12 or more years, and $20 \%$ had $1-5$ years. These women were slightly more educated than the general population of women of reproductive age, $23 \%$ of whom had no schooling.

Number, rate and percentage distribution of pregnancies and their outcomes by intention status, Gujarat, 2015

\begin{tabular}{lrcc}
\hline $\begin{array}{l}\text { Pregnancy intention } \\
\text { status and outcomes }\end{array}$ & No. & $\begin{array}{c}\text { No. per } \mathbf{1 , 0 0 0} \text { women } \\
\text { aged } \mathbf{1 5 - 4 9 *}\end{array}$ & \% distribution \\
\hline Intended & $\mathbf{1 , 1 5 4 , 4 0 0}$ & $\mathbf{6 7 . 7}$ & $\mathbf{4 7 . 5}$ \\
\hline Planned births & 962,000 & 56.4 & 39.6 \\
\hline Miscarriages & 192,400 & 11.3 & 7.9 \\
\hline Unintended & $\mathbf{1 , 2 7 7 , 8 0 0}$ & $\mathbf{7 5 . 0}$ & $\mathbf{5 2 . 5}$ \\
\hline Unplanned births & 320,700 & 18.8 & 13.2 \\
\hline Abortions & 811,800 & 47.6 & 33.4 \\
\hline Miscarriages & 145,300 & 8.5 & 6.0 \\
\hline Total & $\mathbf{2 , 4 3 2 , 2 0 0}$ & $\mathbf{1 4 2 . 7}$ & $\mathbf{1 0 0 . 0}$ \\
\hline
\end{tabular}

*Denominator is $17,048,928$ women aged 15-49. NOTE: Proportions presented in the text, figures and tables may differ slightly because of rounding. SOURCE: See Incidence Methodology. 


\section{Incidence of unintended pregnancy}

Unintended pregnancy is the precursor to most induced abortions and a key indicator of the need for modern contraception and for the services and information that support effective use. Unintended pregnancies may indicate that women are not using a method, are using the method inconsistently or incorrectly, or are using a relatively ineffective traditional method. Understanding the level of unintended pregnancy in Gujarat helps us ascertain the extent to which women need contraceptive and abortion services.

We determined there were approximately 2.4 million pregnancies in Gujarat in 2015. Of these, 47\%—or 1.15 million-were intended, and the remaining 53\%—or 1.28 million-were unintended (Figure 6, page 19). More than half $(64 \%)$ of unintended pregnancies ended in an abortion.

Gujarat's total pregnancy rate was 143 pregnancies per 1,000 women of reproductive age in 2015 (Table 6, page 19). The intended pregnancy rate was 68 , and the unintended pregnancy rate was 75 . There were 56 planned births and 19 unplanned births per 1,000 women aged 15-49.

The high level of unintended pregnancy highlights the need for improved, voluntary and comprehensive contraceptive services for all women of reproductive age -as part of the continuum of care, including in the context of postabortion and postpartum services-to prevent and address unintended pregnancy and unplanned childbearing. 


\section{Incidence of Abortion}

The methodology used by the UPAI study draws heavily on the abortion incidence complications methodology (AICM), an established method for indirectly estimating abortion incidence in countries where safe and unsafe abortion are prevalent but where official statistics are unavailable or highly incomplete. ${ }^{58}$ However, because abortion is broadly legal in India and because drug sales data are available there, our study was able to collect more direct data on abortion provision than has been available in most other countries in which the methodology has been used, and we were able to minimize the proportion of abortions that were estimated by indirect methods. We modified the AICM for India by measuring each of three main components of total abortions separately: (1) facility-based abortions, (2) MMA using medications purchased outside of health facilities without the supervision of a facility provider and (3) abortions occurring outside of health facilities that used methods other than MMA. Data available to measure the first two components are good-quality direct estimates, which, when available, are preferred to indirect estimates. The calculations of the abortion incidence estimates are detailed in Appendix Table 9. In addition to showing the medium estimates presented in the text, the table shows the low and the high estimates, which represent the results of various sensitivity analyses conducted.

Facility-based abortions. As explained in the Survey Methodology, induced abortions (both surgical and medical) obtained at public and private facilities were captured by the HFS. We also compiled data on abortion provision from large NGOs.

Nonfacility MMA. We obtained the number of combipacks (combined mifepristone and misoprostol) and mifepristone-only pills sold in the state in 2015 in the for-profit sector from IMS Health (whose data come from private facility provision and for-profit sales), and the number provided by the nonprofit sector comes mainly from Marie Stopes International and DKT International. Data for a few smaller networks of NGO providers were obtained either from DKT (Population Services International, World Health Partners, Janani) or independently (Parivar Seva Sanstha, Family Planning Association-India). We used only data from 2015, but we examined earlier years and found there was little difference in the number of combipacks sold in the preceding three years. We did not include misoprostol-only sales because that drug has uses other than inducing abortion, and it was not possible to estimate the quantity used specifically to induce abortions. The broad availability of the combipack implies that use of misoprostol alone to induce abortion is likely to be relatively low. However, if misoprostol is still used by a small proportion of women, abortion incidence will be slightly underestimated.

We applied the following adjustments to the for-profit MMA drug sales data to arrive at the corresponding number of abortions performed using the method.

- We adjusted the mifepristone-only data to account for the fact that women may use more than one mifepristone pill to induce an abortion. ${ }^{59}$ We assumed that $80 \%$ of women who purchase mifepristone alone (i.e., not in a combipack) take one $200-\mathrm{mg}$ pill, $10 \%$ take two and $10 \%$ take three. ${ }^{49}$

- We averaged the for-profit sales data among groups of states because some states are focal points for distribution to other states, and sales of MMA in each state do not necessarily reflect use in that state. For-profit sales of MMA drugs in Gujarat, Chandigarh, Delhi, Goa, Haryana, Himachal Pradesh, Jammu and Kashmir, Madhya Pradesh, Maharashtra, Punjab and Rajasthan were combined, and an average number of MMA packets per 1,000 women of reproductive age was calculated and applied to Gujarat's population to estimate the forprofit sales of MMA drugs likely to be used in the state.

- IMS Health reports that their drug sales are $95 \%$ complete, ${ }^{60}$ so we inflated these numbers by $5 \%$ to account for the missing data.

We then summed MMA distributed by nonprofits and the adjusted total sold in for-profit venues, and made the following adjustments:

- On the basis of available studies, we reduced the total by $10 \%$ to account for the proportion of MMA drugs likely lost to wastage. ${ }^{61,62}$

- To avoid double-counting women who attempted an abortion using MMA before obtaining a facility-based abortion, we reduced the sales by an additional $5 \%$ of facility-based abortions. ${ }^{45}$

Finally, we subtracted MMA provided in private and NGO facilities and those given as prescriptions from public facilities to obtain the number of abortions using MMA provided in nonfacility settings in 2015. This was necessary because MMA administered in public facilities (i.e., provided directly by the doctor and not via prescription) is supplied through government tenders and is not included in for-profit or nonprofit drug sales data.

\section{Nonfacility abortions using methods other than MMA. There are no direct} sources of information on the number of abortions occurring outside of facilities that use methods other than MMA, so we estimated these indirectly. Two community-based studies conducted in 2009 provide estimates of the proportion of all women having abortions who do so outside of a facility using a method other than MMA: 8\% in Maharashtra and 6\% in Rajasthan. ${ }^{51,52}$ The proportion of women seeking these types of abortions is expected to have declined with the steady 
rise in MMA use since those studies took place. We therefore adjusted the average of the estimates from these two studies downward to account for rising MMA use and estimated the proportion in 2015 to be $5 \%$ (a drop of approximately $30 \%$ over these six years).

\section{Sensitivity analysis and estimate}

ranges. Because we made several assumptions that introduced a degree of uncertainty to our estimates of both MMA and other abortions occurring outside of facilities, we performed sensitivity analyses around these key assumptions. On the basis of available literature and expert opinions, we established low and high parameters for each assumption described above. In addition, using the sample design of the HFS, we calculated standard errors around the number of facility-based abortions to create confidence intervals around the HFS estimates. Using the results of the sensitivity analysis, combined with the low and high confidence intervals, we estimated a range around the total number of abortions.

\section{Incidence of unintended preg- nancy and total pregnancy}

To calculate unintended pregnancies by state, we summed the numbers of induced abortions, miscarriages attributable to unintended pregnancies, and unplanned births. The number of unintended pregnancies that end in a miscarriage is based on the biological pattern of pregnancy loss and is estimated to be $20 \%$ of unplanned live births plus $10 \%$ of induced abortions. ${ }^{63,64}$ The number of unplanned births comes from multiplying the number of births ${ }^{65}$ by the proportion of the TFR that is unwanted (both the TFR and wanted TFR are from the 2015-2016 NFHS-4). ${ }^{30}$ In Gujarat, the TFR is 2.0 and the wanted TFR is 1.5 , which means that an estimated $25 \%$ of births in the state are unplanned. The number of intended pregnancies was calculated by summing planned births and miscarriages from intended pregnancies (estimated to equal
$20 \%$ of planned live births). The sum of all live births, abortions and miscarriages (from intended and unintended pregnancies) yields the total number of pregnancies.

\section{Calculating abortion rates}

The abortion rate is defined as the number of abortions per 1,000 women aged $15-49$ in a given year. This study provides the estimated number of abortions for 2015, and the number of women of reproductive age was estimated using projections based on the rate of population growth between the 2001 and 2011 India Censuses, assuming the age distribution remained stable between 2011 and $2015 .{ }^{29}$ 


\section{Conclusions and Recommendations}

S

ome of the UPAI study findings are encouraging and provide evidence of gains in regard to the provision of abortion services in Gujarat. For example, most facilities that provide abortion care offer both MMA and surgical abortion, indicating these facilities can tailor care to each case. In addition, the large majority of facilities that offer abortion-related care also report providing contraceptive services, thus contributing vitally to women's continuum of sexual and reproductive health care. ${ }^{47} \mathrm{How}$ ever, our findings also highlight several areas of women's sexual and reproductive health urgently needing attention in Gujarat. The incidence of abortion and related indicators-including high levels of abortion complications-reflect the need for thorough review of the state's ability to meet the needs for safe abortion services and postabortion care. In addition, the substantial level of unintended pregnancy indicates a need to improve contraceptive services to help women avoid unwanted pregnancies.

Moreover, high rates of unintended pregnancy and abortion not only are indicative of women's inadequate access to and ineffective use of modern contraceptives, they also stem from gender inequity - in families and in society more broadly-that restricts women's access to information and services, and may compromise their ability to negotiate contraceptive use when they do not desire a pregnancy. Despite recent trends toward increased age at first marriage, early marriage remains common in India; women and girls continue to face gender discrimination; and access to sexual and reproductive health services, including safe abortion, is limited. Addressing the root causes of son preference and other forms of gender discrimination is critically important and should be pursued hand in hand with efforts to improve access to safe abortion services.

Below, we make recommendations aimed at increasing and improving the provision of abortion-related and contraceptive services. We also address the need to improve collection of data on abortion going forward.

\section{Expanding services}

Our data reveal several areas in which services must be expanded to meet women's needs.

Coverage and location of services. The majority of women in Gujarat obtain abortion-related services through private health facilities, and the majority of these facilities are based in urban areas, despite the fact that more than half of the population of reproductive age-women reside in rural areas. Access to induced abortion care and services to treat postabortion complications is limited for rural women, particularly those who are poor.

PHCs are the first-and often the only-point of contact poor and rural women have with the health system. Yet only $9 \%$ of these facilities offer induced abortion and just $18 \%$ offer postabortion care. This highlights the need to expand service provision by trained providers at PHCs to include both early abortion using MMA and care for abortion complications. One way to improve access to abortion services in underserved areas is to implement a job rotation system whereby trained providers can work in hard-toreach areas on a temporary basis to ensure that coverage is both available and consistent.

Addressing major barriers to abortion provision. Provision of induced abortion is low even among public facilities that would usually be expected to provide that service: An alarming 74\% of CHCs do not offer abortion. One of the key reasons reported in the HFS for why public health facilities do not provide abortion is the lack of equipment and supplies. Adequate funding should be allocated through state Programme Implementation Plans to provide these items on a regular basis and ensure they reach the facilities, and the budgeting system should be simplified to facilitate its accurate use.

A major barrier among private facilities is the lack of registration to provide abortion and the difficulties involved in obtaining such approval. ${ }^{66,67}$ Steps are needed to ensure that the District Level Committees responsible for site approval are in place and functional. In addition, accelerated registration should be implemented for private facilities seeking approval to provide abortion using MMA only. Other strategies to streamline the process include setting up online application options, as has been done in Uttar Pradesh. ${ }^{68}$ Lack of trained providers, another major barrier to provision for both public and private facilities, is discussed below.

Provision of free or affordable services. The majority of women obtaining abortions do so outside of the public sector, where they presumably pay out of pocket for services. However, the costs associated with private-sector care are likely a barrier or a burden for many women. It 
is important to conduct research that collects women's views on the accessibility and acceptability of current abortion-related services and their reasons for seeking care outside of the public sector. Simultaneously, the health system should work to ensure that free or low-cost abortion services in this sector are confidential, youth friendly and nonjudgmental.

Provision beyond the first trimester. Only $22 \%$ of facilities that provide abortions offer them in the second trimester, and although these abortions are less frequently requested than earlier terminations, their availability is vital. The most vulnerable women-including those who are poor, young, unmarried or widowed, and those who are victims of sexual violence-may be most likely to experience delays in seeking abortion services because of transportation issues, social taboos and lack of agency. ${ }^{69}$ These women, along with those who develop severe health complications or who discover fetal anomalies, are the most likely to be negatively affected by the lack of access to procedures at later gestations. Special efforts should be made to ensure that an adequate distribution of public- and private-sector facilities offer second-trimester abortion services.

Also threatening women's access to safe abortion generally, and second-trimester abortion specifically, is the country's reaction to the adverse sex ratio. The government's response, as part of implementation of the PCPNDT Act, has been to restrict abortion services and strictly regulate and monitor providers. Providers have reported that unannounced inspections and harassment by authorities have prompted them to stop providing abortions, especially in the second trimester. ${ }^{70}$ Increased communication between those implementing the law and community-level stakeholders is needed to clarify that not all second-trimester terminations are for the purpose of sex selection, to communicate that women are legally entitled under certain circumstances to second-trimester abortion, and to dispel misconceptions about the legal status of abortion. The MoHFW issued guidance in 2015 for ensuring access to abortion services and addressing gender-biased sex selection, and these guidelines should be fully implemented at the district and provider levels. ${ }^{71}$

\section{Training providers and staff}

HFS data indicate that abortion provision in Gujarat suffers from a lack of qualified providers, and training may be inadequate for those currently providing services. Lack of trained staff is the primary reason public facilities gave for not offering induced abortion services. Expanding the number of qualified, certified abortion providers will require improving access to training and certification for allopathic doctors (those holding MBBS degrees) working in both the public and private sectors. Approving the proposed amendment to the MTP Act that would allow nurses and ANMs, as well as practitioners trained in Indian systems of medicine with recognized qualifications, to provide MMA would further help address this shortfall in providers.

Second, lack of training is likely a major reason for the overuse of invasive surgical abortion techniques (particularly during the first trimester) observed in the HFS and other sources. ${ }^{72}$ Providers should be routinely updated on WHO and national guidelines for abortion provision. In addition, they should be trained (or retrained, as necessary) in recommended techniques, especially MMA and vacuum aspiration.

Third, staff at health facilities sometimes turn away women seeking abortions for reasons that do not accurately reflect legal restrictions or the facility's capacity to provide abortion. Providers who deny services because they perceive a patient as being too young or because she is not married or does not have family members' consent may be acting on bias rather than following guidelines. Regular efforts should be made to ensure that health care providers and other facility staff do not impose unnecessary limitations on abortion provision.

Lastly, social stigma related to abortion creates a barrier to the use of safe services, even where they are offered. This barrier is likely to negatively affect certain vulnerable groups more than other women; unmarried women, for instance, likely face strong stigma because of taboos against premarital sexual activity. ${ }^{72}$ Health care providers can help to protect their clients from the potential social costs of seeking an abortion by offering private and confidential services. This calls for training of public-sector staff involved in providing abortions services on so-called soft skills, such as respecting women's privacy and maintaining nonjudgmental attitudes. Accredited social health activists (ASHAs) and ANMs should be priority recipients of such training because they are often the first point of contact for women seeking abortion. In addition, facilities can work to increase the confidentiality of health care visits, including by conducting consultations behind privacy screens and adopting protocols for speaking to women about sensitive or taboo issues to reassure them that their identity is being protected.

\section{Educating the public about induced abortion}

Providers report that some women seeking abortion may have gaps in their understanding about the circumstances under which it is permitted and where to obtain safe and legal services. Reaching communities with social awareness programs will require working on multiple fronts and engaging a variety of community-based groups. Strategies could include the following: 
- Educating providers in order to counteract misinformation about the legal status of abortion. ${ }^{72}$

- Orienting ASHAs and ANMs on abortion-related information. Although these health workers do not perform abortions, they are in frequent touch with the community and have the opportunity to inform women who want to terminate a pregnancy on the law and where to obtain safe services.

- Displaying information at public health facilities that educates visitors about the legality of abortion, safe methods of abortion, and the risks involved in using unsafe methods, going to unqualified providers or using MMA incorrectly.

- Including information about abortion during all types of sexual and reproductive health visits. This would help to reach the large proportions of women who have an institutional delivery and make prenatal care visits, as well as those obtaining contraceptive counseling.

- Actively disseminating the Government of India's mass media campaign Making Abortion Safer, which was aired on television channels nationally. ${ }^{73}$ Efforts could be made to tailor its messages to specific target audiences.

- Offering culturally sensitive sexuality education-both in and out of school settings-to ensure that young people are provided with age-appropriate and accurate information related to all aspects of their sexual and reproductive lives, including information about contraception and abortion.

\section{Improving MMA services}

MMA is safe and highly effective when the correct regimen is followed, and increased provision of this method, both in health facilities and in nonfacility settings, has improved access to abortion care. It has also likely reduced severe abortion-related morbidity: Available data on MMA drug distribution indicate that its use has been replacing the use of traditional and less safe methods of abortion. ${ }^{74}$ Continuing to expand MMA provision would likely lead to further reductions in abortion morbidity.

At the same time, the implication in the HFS data that normal bleeding associated with MMA is sometimes misdiagnosed as a complication suggests that women who obtain MMA outside of facilities may be inadequately informed about the method or may have been given incorrect advice to seek treatment in facilities as soon as bleeding begins. In addition, the safety and effectiveness of MMA depend to some extent on the quality of the information given and the user's adherence to the protocol.

Some strategies to facilitate proper use of MMA include ensuring combipacks have clear and simple instructions in multiple languages, as well as pictorial instructions for women with low literacy. The inserts should describe the regimen and expected symptoms, and should indicate where to go in case of complications. In addition, it may be beneficial to set up a telephone helpline to provide information to users, to ensure that women who use MMA in a nonfacility setting can do so safely. The helpline number could be printed prominently on MMA packaging and displayed at pharmacies.

Because the great majority of abortions in Gujarat-four out of every five-use MMA obtained outside of a health facility, there is a particular need to find out more about the women who obtain MMA this way, their reasons for not using facility-based services, the type of provider they go to and their knowledge of the regimen (e.g., awareness of protocols and normal bleeding). In addition, we need to know more about the extent to which women who seek treatment for complications after taking MMA outside of a facility experience complications that require treatment and the costs they incur.

\section{Improving access to and quality of postabortion care services}

Many of the strategies that will improve abortion services will have the added benefit of improving postabortion care. For instance, increased training in abortion techniques will also bolster the provider skills needed for postabortion care; training about abortion law, countering stigma and providing confidential services will improve providers' abilities to give high-quality care to patients experiencing abortion complications; and strategies to increase publicsector provision of abortion and postabortion care will go hand in hand.

Other steps can be taken to specifically address the need for improved postabortion care. HFS data show that most complications reported in 2015 were relatively minor, such as bleeding and other non-life-threatening complications resulting from use of MMA without professional guidance. With proper training, relatively low-level medical staff can address these types of complications, and specialized training of a wide provider base in treating these complications would greatly increase access to treatment. In addition, a small but notable proportion of women experience severe complications, so providers should also be trained in best practices for treating infection, sepsis, shock and physical injuries caused by unsafe abortion.

\section{Ensuring availability and correct use of contraceptives}

Unmet need for contraception in Gujarat contributes to the state's fairly high level of unintended pregnancy. Using this evidence, the state should continue to promote access to contraception but also take additional steps to ensure women and couples are able to meet their fertility goals, including by offering a range of contraceptive methods and 
improving counseling on how to use them correctly and consistently. The Government of India already recognizes this need and has included it in its postabortion family planning guidelines. ${ }^{75}$ The rollout of these guidelines should be prioritized to strengthen women's access to postabortion contraceptive care.

Although nearly all facilities reported in the HFS that they offer contraceptives to abortion clients and postabortion care patients, ${ }^{47}$ uptake of modern methods (aside from female sterilization) is still low. This may signal an unmet need for reversible modern contraception for women who want to delay childbearing. It is important to ensure comprehensive, high-quality contraceptive counseling that addresses women's concerns about use and helps them find the method that best suits them. Failure to provide contraceptive counseling to this segment of the population is a missed opportunity to help women prevent subsequent unintended pregnancies and abortions.

\section{Improving data collection}

To obtain a more complete picture of abortion and postabortion care-and thus improve the government's ability to address gaps in and barriers to abortion-related services-the MoHFW needs to expand its data collection. Doing so will require making sure the Health Management Information System more comprehensively captures abortion-related services provided in public and registered private facilities. Improving the process for registering private health facilities that provide only MMA and meet requirements for providing this service would create a formal channel for such facilities to report the services they provide, improving the overall coverage of official abortion statistics. Both public and private providers would need to be sensitized about the importance of keeping records on abortion data for reporting to the MoHFW and how to do so correctly and confidentially.

Mechanisms should also be put in place to periodically monitor the quality of abortion services at all levels of public and private facilities. Improving the documentation of abortion service statistics would allow the government to understand on a consistent basis the quality and scope of the services being provided and to gauge the need for improvement or expansion.

\section{The way forward}

Improving and expanding abortion and postabortion care is an important step toward bettering overall measures of sexual and reproductive health in Gujarat. Greater sexual and reproductive health, in turn, improves the status of women and the well-being of individuals, families and communities. Action must be taken on multiple fronts. Our study's findings provide support for an array of policy and program actions, and for current and ongoing efforts to increase access to and quality of abortion-related services. In addition, our estimates of unintended pregnancy highlight the need for comprehensive contraceptive services-as part of the continuum of care for all women of reproductive age and, specifically, as part of postabortion and postpartum services - to prevent and address unintended pregnancy and unplanned childbearing. Whatever steps are taken must include and prioritize the needs of disadvantaged groups, including poor and rural women, ensuring that no groups are left behind. 


\section{References}

1. Ministry of Health and Family Welfare (MoHFW), Health and Family Welfare Statistics of India 2015, New Delhi: MoHFW, Statistics Division, 2015.

2. Duggal $R$ and Ramachandran $V$, Abortion Assessment Project-India: Summary and Key Findings, Mumbai: Centre for Enquiry into Health and Allied Themes and Healthwatch, 2004.

3. Sebastian M, Khan M and Sebastian D, Unintended Pregnancy and Abortion in India with Focus on Bihar, Madhya Pradesh and Odisha, New Delhi: Population Council, 2014.

4. Stillman $\mathrm{M}$ et al., Abortion in India: A Literature Review, New York: Guttmacher Institute, 2014, www.guttmacher.org/report/abortion-indialiterature-review.

5. Winikoff B and Sheldon W, Use of medicines changing the face of abortion, International Perspectives on Sexual and Reproductive Health, 2012, 38(3):164-166.

6. Singh $\mathrm{S}$ et al., The incidence of menstrual regulation procedures and abortion in Bangladesh, 2014, International Perspectives on Sexual and Reproductive Health, 2017, 43(1):1-11.

7. Sathar $Z$ et al., Induced abortions and unintended pregnancies in Pakistan, Studies in Family Planning, 2014, 45(4):471-491, doi:10.1111/ j.1728-4465.2014.00004.x

8. Puri $\mathrm{M}$ et al., Abortion incidence and unintended pregnancy in Nepal, International Perspectives on Sexual and Reproductive Health, 2017, 42(4):197-209

9. Government of India, Medical Termination of Pregnancy Act, Act No. 34, 1971.

10. Aich P et al., Situation Analysis of MTP Services in Bihar: FebruaryMay 2011, New Delhi: Ipas-India, 2011.

11. Aich P et al., Situation Analysis of MTP Services: Jharkhand, FebruaryMay 2011, New Delhi: Ipas-India, 2011.

12. Iyengar S, Situational Analysis of Abortion Services in Rajasthan, Udaipur, India: Action, Research and Training for Health, 2005.

13. Barge $S$ et al., Formal and Informal Abortion Services in Rajasthan, India: Results of a Situation Analysis, New Delhi: Population Council, 2004.

14. MoHFW, Comprehensive Abortion Care: Training and Service Delivery Guidelines, New Delhi: MoHFW, 2010.

15. Government of India, The Medical Termination of Pregnancy (Amendment) Act, 2002.

16. Government of India, The Medical Termination of Pregnancy Rules (Amendment), 2003.

17. MoHFW, Medical Termination of Pregnancy Regulations 2003, 2003, https://betivadhaao.gujarat.gov.in/dwnld/MTP_Regulations_notification. pdf.

18. Directorate General of Health Services, Government of India, FDC of Combipack of Mifepristone+Misoprostol Tablet, New Delhi: Central Drugs Standard Control Organisation, 2008.

19. MoHFW, Draft Medical Termination of Pregnancy (Amendment) Bill, 2014.

20. Office of the Registrar General and Census Commissioner, Sample Registration System Statistical Report 2016, New Delhi: Ministry of Home Affairs, Government of India, 2017.

21. Government of India, Pre-Natal Diagnostic Techniques (Regulation and Prevention of Misuse) Act, No. 57 of 1994.

22. Government of India, Amendment to the Pre-Conception and Pre-Natal Diagnostic Techniques (Prohibition Of Sex Selection) Act, 2003.

23. Government of India, Pre-Natal Diagnostic Techniques (Regulation and Prevention of Misuse) Amendment Act, No. 14 of 2003.

24. Nidadavolu $V$ and Bracken $H$, Abortion and sex determination: conflicting messages in information materials in a District of Rajasthan, India, Reproductive Health Matters, 2006, 14(27):160-171, doi:10.1016/S0968-8080(06)27228-8

25. Shidhaye PR et al., Study of knowledge and attitude regarding prenatal diagnostic techniques act among the pregnant women at a tertiary care teaching hospital in Mumbai, Journal of Education and Health Promotion, 2012, 1:36, doi:10.4103/2277-9531.102049.

26. Yasmin $S$ et al., Gender preference and awareness regarding sex determination among antenatal mothers attending a medical college of eastern India, Scandinavian Journal of Public Health, 2013, 41(4):344350, doi:10.1177/1403494813478694.

27. Banerjee $\mathrm{S}$ et al., Accreditation of Private Sector Health Facilities for Provision of Comprehensive Abortion Care Services, New Delhi: IpasIndia, 2013.

28. Sahoo H, special tabulations of data from the DLHS-4

29. International Institute for Population Sciences (IIPS), special tabulations of population growth data from the 2001-2011 Censuses.

30. IIPS and ICF, National Family Health Survey (NFHS-4), India, 2015-16. Gujarat, Mumbai: IIPS, 2017.

31. Government of India Planning Commission, Press Note on Poverty Estimates, 2011-2012, New Delhi: Government of India Planning Commission, 2013.

32. IIPS and ICF, National Family Health Survey (NFHS-4), India, 2015-16, Mumbai: IIPS, 2017

33. IIPS and Macro International, National Family Health Survey (NFHS-3), India, 2005-06: Gujarat, Mumbai: IIPS, 2007.

34. IIPS and Macro International, National Family Health Survey (NFHS-2), India, 1998-99: Gujarat, Mumbai: IIPS, 2000.

35. Banerjee $\mathrm{S}$, Indirect estimation of induced abortion in India, working paper, New Delhi: Ipas Development Foundation, 2012.

36. MoHFW, Health and Family Welfare Statistics of India, 2011, New Delhi: MoHFW, Statistics Division, 2011

37. Registrar General and Census Commission of India, Population enumeration data, C-14 five year age group, 2018, http://www. censusindia.gov.in/2011 census/C-series/C-14.html.

38. Barge $S$ et al., Availability and quality of MTP services in Gujarat, Maharashtra, Tamil Nadu and Uttar Pradesh, Working Paper, Vadodara, India: Centre for Operations Research \& Training, 1998, No. 13.

39. Khan M, Barge S and Kumar N, Availability and access to abortion services in India: myths and realities, paper presented at the annual meeting of the International Union for the Scientific Study of Population, Salvador de Bahia, Brazil, Aug. 18-24, 2001.

40. Khan ME et al., Situational analysis of medical termination of pregnancy services in Gujarat, Maharashtra, Tamil Nadu and Uttar Pradesh, paper presented at the International Workshop on Abortion Facilities and Post-Abortion Care and Operations Research, New York, Jan. 19-21, 1998

41. Barua $A$, Abortion care in urban slums: the case of Ahmedabad, in: Visaria L and Ramachandran V, eds., Abortion in India: Ground Realities, New York: Routledge, 2007, p., https://repository.library. georgetown.edu/handle/10822/967464

42. Banerjee $S$ and Andersen Clark K, Exploring the Pathways of Unsafe Abortion: A Prospective Study of Abortion Clients in Selected Hospitals of Madhya Pradesh, India, New Delhi: Ipas-India, 2009.

43. Jejeebhoy S, Zavier A and Kalyanwala S, Assessing Abortion-Related Experiences and Needs in Four Districts of Maharashtra and Rajasthan, 2006, New Delhi: Population Council, 2010.

44. Elul B et al., Unwanted Pregnancy and Induced Abortion in Rajasthan, India: A Qualitative Exploration, New Delhi: Population Council, 2004.

45. Kumar R et al., Unsuccessful prior attempts to terminate pregnancy among women seeking first trimester abortion at registered facilities in Bihar and Jharkhand, India, Journal of Biosocial Science, 2013, 45(2):205-215, doi:10.1017/S0021932012000533.

46. Visaria $L$ et al., Abortion in India: emerging issues from the qualitative studies, Economic and Political Weekly, 2004, 39(46-47):5044-5052.

47. IIPS, Population Council and Guttmacher Institute, Provision of abortion and postabortion services in Gujarat, 2015, Fact Sheet Mumbai: IIPS; and New York: Guttmacher Institute, 2018 
48. World Health Organization (WHO), Clinical Practice Handbook for Safe Abortion, Geneva: WHO, 2014

49. Sheriar N, formerly of the Federation of Obstetrics and Gynecological Societies of India, Mumbai, personal communication, Aug. 2, 2017.

50. Creinin MD and Gemzell-Danielsson K, Medical abortion in early pregnancy, in: Paul M et al., eds., Management of Unintended and Abnormal Pregnancy: Comprehensive Abortion Care, Hoboken, NJ: Wiley-Blackwell, 2009, pp. 111-134.

51. Jejeebhoy S et al., Increasing Access to Safe Abortion in Rural Maharashtra: Outcomes of a Comprehensive Abortion Care Model, New Delhi: Population Council, 2011

52. Jejeebhoy S et al., Increasing Access to Safe Abortion in Rural Rajasthan: Outcomes of a Comprehensive Abortion Care Model, New Delhi: Population Council, 2011.

53. Stillman $M$ et al., Unintended Pregnancy, Abortion and Postabortion Care in Bihar, India-2015, New York: Guttmacher Institute, 2018.

54. Alagarajan $\mathrm{M}$ et al., Unintended Pregnancy, Abortion and Postabortion Care in Tamil Nadu, India-2015, New York: Guttmacher Institute, 2018.

55. Hussain R et al., Unintended Pregnancy, Abortion and Postabortion Care in Madhya Pradesh, India-2015, New York: Guttmacher Institute, 2018.

56. Shekhar $\mathrm{C}$ et al., Unintended Pregnancy, Abortion and Postabortion Care in Uttar Pradesh, India-2015, New York: Guttmacher Institute, 2018.

57. Pradhan MR et al., Unintended Pregnancy, Abortion and Postabortion Care in Assam, India-2015, New York: Guttmacher Institute, 2018.

58. Singh S, Prada E and Juarez F, The Abortion Incidence Complications Method: a quantitative technique, in: Singh S, Remez $L$ and Tartaglione A, eds., Methodologies for Estimating Abortion Incidence and Abortion-Related Morbidity: A Review, New York: Guttmacher Institute, 2010, pp. 71-98.

59. Elul B et al., Are obstetrician-gynecologists in India aware of and providing medical abortion?, Journal of Obstetrics and Gynecology India, 2006, 56(4):340-345.

60. Kumar M, IMS Health: a brief introduction, slide presentation, Mumbai: IMS Health, 2014

61. Vlassoff $M$ et al., Cost-effectiveness of two interventions for the prevention of postpartum hemorrhage in Senegal, International Journal of Gynecology and Obstetrics, 2016, 133(3):307-311.

62. Seligman B and Xingzhu L, Policy and Financing Analysis of Selected Postpartum Hemorrhage Interventions: Country Summary, Rockville, MD, USA: Abt Associates, 2006

63. Harlap S, Shiono P and Ramcharan S, A life table of spontaneous abortions and the effects of age, parity and other variables, in: Porter I and Hook E, eds., Human Embryonic and Fetal Death, New York: Academic Press, 1980, pp. 145-158.

64. Bongaarts $\mathrm{J}$ and Potter R, Fertility, Biology, and Behavior: An Analysis of the Proximate Determinants, New York: Academic Press, 1983.

65. Ram U, IIPS, Mumbai, special tabulations of birth data from the 2015 Sample Registration Survey.

66. Hirve $S$, Abortion law, policy and services in India: a critical review, Reproductive Health Matters, 2004, 12(24):114-121.

67. Dalvie SS, Second trimester abortions in India, Reproductive Health Matters, 2008, 16(31 Suppl.):37-45, doi:10.1016/S09688080(08)31384-6.

68. National Health Mission Uttar Pradesh, Approval of private clinics for Comprehensive Abortion Care (CAC) services, 2017, http:// cacuttarpradesh.in/registration.php.

69. Jejeebhoy SJ et al., Experience seeking abortion among unmarried young women in Bihar and Jharkhand, India: delays and disadvantages, Reproductive Health Matters, 2010, 18(1460-9576):163-174, doi:10.1016/S0968-8080(10)35504-2.
70. Potdar P et al., "If a woman has even one daughter, I refuse to perform the abortion": Sex determination and safe abortion in India, Reproductive Health Matters, 2015, 23(45):114-125, doi:10.1016/j. rhm.2015.06.003.

71. MoHFW, Ensuring Access to Safe Abortion and Addressing Gender Biased Sex Selection, New Delhi: MoHFW, 2015.

72. Sjöström S et al., Medical students are afraid to include abortion in their future practices: in-depth interviews in Maharastra, India, BMC Medical Education, 2016, 16:8, doi:10.1186/s12909-016-0532-5.

73. Ipas-India and MoHFW, National Consultation on Comprehensive Abortion Care for Women: Roadmap for Increasing Access: A Brief Report, New Delhi: Ipas-India, 2016.

74. Banerjee $S$, Abortion method, provider, and cost in transition: experience of Indian women seeking abortion over the last twelve years (2004-2015), paper presented at the International Population Conference, Cape Town, South Africa, Oct. 29-Nov. 3, 2017.

75. Family Planning Division, MoHFW, Post Abortion Family Planning: Technical Update, New Delhi: Government of India, 2016. 


\section{Appendix Tables}


Percentage distribution of public and private facilities offering abortion-related services, according to urban or rural location, Gujarat, 2015

\begin{tabular}{|c|c|c|c|c|c|c|c|c|c|}
\hline \multirow[b]{2}{*}{ Facilities } & \multicolumn{3}{|c|}{ Offering induced abortion } & \multicolumn{3}{|c|}{ Offering postabortion care } & \multicolumn{3}{|c|}{$\begin{array}{l}\text { Offering any abortion-related } \\
\text { services }\end{array}$} \\
\hline & Total & Urban & Rural & Total & Urban & Rural & Total & Urban & Rural \\
\hline All & 100.0 & 100.0 & 100.0 & 100.0 & 100.0 & 100.0 & 100.0 & 100.0 & 100.0 \\
\hline Public & 18.4 & 8.6 & 48.6 & 22.1 & 9.0 & 51.0 & 21.1 & 8.1 & 50.4 \\
\hline Private & 81.6 & 91.4 & 51.4 & 77.9 & 91.0 & 49.0 & 78.9 & 91.9 & 49.6 \\
\hline No. (weighted) & 1,392 & 1,050 & 342 & 2,038 & 1,403 & 635 & 2,294 & 1,589 & 705 \\
\hline Public & 100.0 & 100.0 & 100.0 & 100.0 & 100.0 & 100.0 & 100.0 & 100.0 & 100.0 \\
\hline Hospitals & 28.1 & 77.3 & 1.4 & 19.7 & 68.5 & 0.7 & 18.9 & 69.1 & 0.7 \\
\hline $\mathrm{CHCs}$ & 31.2 & 16.0 & 39.5 & 33.4 & 25.3 & 36.5 & 33.8 & 24.8 & 37.0 \\
\hline $\mathrm{PHCs}$ & 38.3 & 0.0 & 59.1 & 45.5 & 1.3 & 62.8 & 46.1 & 1.3 & 62.3 \\
\hline Urban public & 2.4 & 6.7 & 0.0 & 1.4 & 4.8 & 0.0 & 1.3 & 4.7 & 0.0 \\
\hline No. (weighted) & 257 & 90 & 166 & 450 & 126 & 324 & 484 & 129 & 355 \\
\hline Private & 100.0 & 100.0 & 100.0 & 100.0 & 100.0 & 100.0 & 100.0 & 100.0 & 100.0 \\
\hline Hospitals & 18.0 & 18.0 & 17.9 & 18.2 & 19.4 & 13.3 & 19.3 & 19.7 & 17.4 \\
\hline $\begin{array}{l}\text { Nursing and } \\
\text { maternity homes }\end{array}$ & 78.9 & 78.3 & 82.1 & 75.9 & 74.8 & 80.4 & 75.6 & 75.3 & 77.0 \\
\hline Clinics & 3.1 & 3.7 & 0.0 & 5.9 & 5.8 & 6.3 & 5.2 & 5.1 & 5.6 \\
\hline No. (weighted) & 1,135 & 959 & 176 & 1,588 & 1,277 & 311 & 1,811 & 1,461 & 350 \\
\hline
\end{tabular}

Notes: Postabortion care refers to care for complications resulting from either induced abortion or miscarriage.

$\mathrm{CHC}=$ community health centre. $\mathrm{PHC}=$ primary health centre. Proportions presented in the text, figures and tables may differ slightly because of rounding. Source: Health Facilities Survey. 
Among facilities providing induced abortion, percentage distribution by method offered and facility type, Gujarat, 2015

\begin{tabular}{|c|c|c|c|c|c|}
\hline \multirow[b]{2}{*}{ Facilities } & \multirow[b]{2}{*}{$\begin{array}{c}\text { Weighted no. } \\
\text { offering abortion }\end{array}$} & \multicolumn{4}{|c|}{$\%$ distribution of facilities by method category } \\
\hline & & Only MMA & $\begin{array}{l}\text { Only surgical } \\
\text { abortion }\end{array}$ & $\begin{array}{l}\text { Both MMA and } \\
\text { surgical abortion }\end{array}$ & Total \\
\hline All & 1,392 & 12.2 & 11.9 & 75.9 & 100.0 \\
\hline Public & 257 & 25.4 & 15.9 & 58.7 & 100.0 \\
\hline Hospitals & 72 & 0.0 & 15.6 & 84.4 & 100.0 \\
\hline $\mathrm{CHCs}$ & 80 & 38.3 & 16.4 & 45.3 & 100.0 \\
\hline $\mathrm{PHCs}$ & 98 & 35.0 & 16.7 & 48.3 & 100.0 \\
\hline Urban public & 6 & 0.0 & 0.0 & 100.0 & 100.0 \\
\hline Private & 1,135 & 9.2 & 10.9 & 79.8 & 100.0 \\
\hline Hospitals & 205 & 7.8 & 17.7 & 74.5 & 100.0 \\
\hline $\begin{array}{l}\text { Nursing and maternity } \\
\text { homes }\end{array}$ & 895 & 8.0 & 9.8 & 82.2 & 100.0 \\
\hline Clinics & 36 & 49.4 & 0.0 & 50.6 & 100.0 \\
\hline
\end{tabular}

Notes: MMA=medical methods of abortion. Surgical abortion=dilatation and curettage, dilatation and evacuation, and vacuum aspiration. $\mathrm{CHC}=$ community health centre. $\mathrm{PHC}=$ primary health centre.

Proportions presented in the text, figures and tables may differ slightly because of rounding. Source: Health Facilities Survey. 
APPENDIX TABLE 3

Number of facilities providing postabortion care and proportion offering these services 24 hours a day, seven days a week, by facility type and location, Gujarat, 2015

\begin{tabular}{|c|c|c|}
\hline Facilities & $\begin{array}{c}\text { Weighted no. of } \\
\text { facilities offering PAC } \\
\text { services }\end{array}$ & $\begin{array}{c}\% \text { of facilities } \\
\text { offering PAC that } \\
\text { offer it 24-7 } \\
\end{array}$ \\
\hline ALL & 2,038 & 84.8 \\
\hline \multicolumn{3}{|l|}{ OWNERSHIP } \\
\hline Public & 450 & 74.1 \\
\hline Hospitals & 89 & 98.6 \\
\hline $\mathrm{CHCs}$ & 150 & 86.6 \\
\hline PHCs & 205 & 57.6 \\
\hline Urban public & 6 & 100.0 \\
\hline Private & 1,588 & 88.8 \\
\hline Hospitals & 289 & 95.3 \\
\hline Nursing and maternity homes & 1,205 & 88.8 \\
\hline Clinics & 94 & 70.4 \\
\hline \multicolumn{3}{|l|}{ LOCATION } \\
\hline Urban & 1,403 & 89.6 \\
\hline Public & 126 & 99.2 \\
\hline Private & 1,277 & 88.6 \\
\hline Rural & 635 & 76.1 \\
\hline Public & 324 & 66.4 \\
\hline Private & 311 & 89.5 \\
\hline
\end{tabular}

Notes: PAC=postabortion care; refers to care for complications resulting from either induced abortion or miscarriage. $\mathrm{CHC}=$ community health centre.

$\mathrm{PHC}=$ primary health centre. Proportions presented in the text, figures and tables may differ slightly because of rounding. Source: Health Facilities Survey. 
Weighted total number of facility-based abortions, average annual number of abortions provided by facilities and percentage distribution of abortions, by facility type, Gujarat, 2015

\begin{tabular}{|c|c|c|c|c|c|}
\hline \multirow[b]{2}{*}{ Facilities } & \multirow[b]{2}{*}{$\begin{array}{c}\text { Annual no. of } \\
\text { facility-based } \\
\text { abortions }\end{array}$} & \multirow[b]{2}{*}{$\begin{array}{l}\text { No. of facilities } \\
\text { offering abortion }\end{array}$} & \multirow[b]{2}{*}{$\begin{array}{l}\text { Average annual } \\
\text { no. of abortion } \\
\text { cases per facility }\end{array}$} & \multicolumn{2}{|c|}{$\begin{array}{c}\% \text { distribution of abortions by } \\
\text { facility type }\end{array}$} \\
\hline & & & & $\begin{array}{c}\text { Within ownership } \\
\text { categories }\end{array}$ & Overall \\
\hline All & 120,800 & 1,392 & 90 & 100.0 & 100.0 \\
\hline Public & 22,400 & 257 & 90 & 100.0 & 18.6 \\
\hline Hospitals & 15,200 & 72 & 210 & 67.7 & 12.6 \\
\hline $\mathrm{CHCs}$ & 3,200 & 80 & 40 & 14.2 & 2.6 \\
\hline $\mathrm{PHCs}$ & 2,800 & 98 & 30 & 12.5 & 2.3 \\
\hline Urban public & 1,200 & 6 & 200 & 5.5 & 1.0 \\
\hline Private & 98,300 & 1,135 & 90 & 100.0 & 81.4 \\
\hline Hospitals & 15,300 & 205 & 70 & 15.5 & 12.6 \\
\hline Nursing and maternity homes & 76,000 & 895 & 80 & 77.3 & 63.0 \\
\hline Clinics & 7,000 & 36 & 200 & 7.1 & 5.8 \\
\hline Private registered & 87,800 & 990 & 90 & 100.0 & 72.7 \\
\hline Hospitals & 14,800 & 189 & 80 & 16.8 & 12.2 \\
\hline Nursing and maternity homes & 66,500 & 784 & 80 & 75.8 & 55.1 \\
\hline Clinics & 6,500 & 18 & 360 & 7.4 & 5.4 \\
\hline Private unregistered & 10,500 & 145 & 70 & 100.0 & 8.7 \\
\hline Hospitals & 500 & 16 & 30 & 4.5 & 0.4 \\
\hline Nursing and maternity homes & 9,500 & 112 & 90 & 90.5 & 7.9 \\
\hline Clinics & 500 & 18 & 30 & 5.0 & 0.4 \\
\hline
\end{tabular}

Notes: $\mathrm{CHC}=$ community health centre. $\mathrm{PHC}=$ primary health centre. Total excludes a small number of abortions provided by NGOs not included in the HFS. Numbers may not add to totals because of rounding. Proportions presented in the text, figures and tables may differ slightly because of rounding. Source: Health Facilities Survey. 
Percentage distribution of facility-based abortions by gestational duration and by trimester, according to facility type, Gujarat, 2015

\begin{tabular}{|c|c|c|c|c|c|c|c|c|c|}
\hline \multirow[b]{2}{*}{ Facilities } & \multirow{2}{*}{$\begin{array}{c}\text { Annual no. of } \\
\text { facility-based } \\
\text { abortions }\end{array}$} & \multicolumn{5}{|c|}{$\%$ distribution by gestational duration } & \multicolumn{3}{|c|}{$\%$ distribution by trimester } \\
\hline & & $\begin{array}{c}<8 \\
\text { weeks }\end{array}$ & $\begin{array}{c}8-12 \\
\text { weeks }\end{array}$ & $\begin{array}{l}13-20 \\
\text { weeks }\end{array}$ & $\begin{array}{c}>20 \\
\text { weeks }\end{array}$ & Total & First & Second & Total \\
\hline All & 120,800 & 67.8 & 28.3 & 3.9 & 0.0 & 100.0 & 96.1 & 3.9 & 100.0 \\
\hline Public & 22,400 & 55.4 & 37.0 & 7.6 & 0.0 & 100.0 & 92.4 & 7.6 & 100.0 \\
\hline Hospitals* & 15,200 & 46.5 & 42.3 & 11.2 & 0.0 & 100.0 & 88.8 & 11.2 & 100.0 \\
\hline $\mathrm{CHCs}$ & 3,200 & 82.8 & 17.2 & 0.0 & 0.0 & 100.0 & 100.0 & 0.0 & 100.0 \\
\hline PHCs & 2,800 & 52.6 & 47.4 & 0.0 & 0.0 & 100.0 & 100.0 & 0.0 & 100.0 \\
\hline Urban public & 1,200 & 100.0 & 0.0 & 0.0 & 0.0 & 100.0 & 100.0 & 0.0 & 100.0 \\
\hline Private & 98,300 & 70.7 & 26.3 & 3.0 & 0.0 & 100.0 & 97.0 & 3.0 & 100.0 \\
\hline Hospitals & 15,300 & 69.5 & 24.9 & 5.6 & 0.0 & 100.0 & 94.4 & 5.6 & 100.0 \\
\hline $\begin{array}{l}\text { Nursing and maternity } \\
\text { homes }\end{array}$ & 76,000 & 69.1 & 28.2 & 2.8 & 0.0 & 100.0 & 97.2 & 2.8 & 100.0 \\
\hline Clinics & 7,000 & 90.8 & 9.2 & 0.0 & 0.0 & 100.0 & 100.0 & 0.0 & 100.0 \\
\hline Private registered & 87,800 & 74.0 & 22.6 & 3.4 & 0.0 & 100.0 & 96.6 & 3.4 & 100.0 \\
\hline Hospitals & 14,800 & 68.5 & 25.7 & 5.8 & 0.0 & 100.0 & 94.2 & 5.8 & 100.0 \\
\hline $\begin{array}{l}\text { Nursing and maternity } \\
\text { homes }\end{array}$ & 66,500 & 73.7 & 23.2 & 3.1 & 0.0 & 100.0 & 96.9 & 3.1 & 100.0 \\
\hline Clinics & 6,500 & 90.0 & 10.0 & 0.0 & 0.0 & 100.0 & 100.0 & 0.0 & 100.0 \\
\hline Private unregistered & 10,500 & 43.0 & 57.0 & 0.0 & 0.0 & 100.0 & 100.0 & 0.0 & 100.0 \\
\hline Hospitals & 500 & 100.0 & 0.0 & 0.0 & 0.0 & 100.0 & 100.0 & 0.0 & 100.0 \\
\hline $\begin{array}{l}\text { Nursing and maternity } \\
\text { homes }\end{array}$ & 9,500 & 37.0 & 63.0 & 0.0 & 0.0 & 100.0 & 100.0 & 0.0 & 100.0 \\
\hline Clinics & 500 & 100.0 & 0.0 & 0.0 & 0.0 & 100.0 & 100.0 & 0.0 & 100.0 \\
\hline
\end{tabular}

Notes: $\mathrm{CHC}=$ community health centre. $\mathrm{PHC}=$ primary health centre. Total excludes a small number of abortions provided by NGOs not included in the HFS. Numbers may not add to totals because of rounding. Proportions presented in the text, figures and tables may differ slightly because of rounding. Source: Health Facilities Survey. 
Percentage distribution of facility-based abortions by method, according to facility type, Gujarat, 2015

\begin{tabular}{|c|c|c|c|c|c|c|c|c|}
\hline \multirow[b]{3}{*}{ Facilities } & \multirow{3}{*}{$\begin{array}{l}\text { Annual no. of } \\
\text { facility-based } \\
\text { abortions }\end{array}$} & \multicolumn{7}{|c|}{$\%$ distribution of abortions by method } \\
\hline & & \multirow[b]{2}{*}{ MMA } & \multicolumn{5}{|c|}{ Surgical } & \multirow[b]{2}{*}{ Total } \\
\hline & & & All & MVA & EVA & $\begin{array}{l}\text { D\&C or } \\
\text { D\&E }\end{array}$ & Other & \\
\hline All & 120,800 & 41.2 & 58.8 & 6.7 & 24.4 & 27.7 & 0.1 & 100.0 \\
\hline Public & 22,400 & 29.9 & 70.1 & 22.7 & 26.0 & 21.1 & 0.3 & 100.0 \\
\hline Hospitals & 15,200 & 18.9 & 81.1 & 23.8 & 33.7 & 23.1 & 0.5 & 100.0 \\
\hline $\mathrm{CHCs}$ & 3,200 & 53.5 & 46.5 & 7.6 & 17.2 & 21.7 & 0.0 & 100.0 \\
\hline PHCs & 2,800 & 47.9 & 52.1 & 38.5 & 0.0 & 13.6 & 0.0 & 100.0 \\
\hline Urban public & 1,200 & 62.5 & 37.5 & 12.5 & 12.5 & 12.5 & 0.0 & 100.0 \\
\hline Private & 98,300 & 43.8 & 56.2 & 3.0 & 24.0 & 29.2 & 0.0 & 100.0 \\
\hline Hospitals & 15,300 & 53.5 & 46.5 & 10.6 & 15.4 & 20.4 & 0.0 & 100.0 \\
\hline $\begin{array}{l}\text { Nursing and maternity } \\
\text { homes }\end{array}$ & 76,000 & 40.9 & 59.1 & 1.8 & 23.7 & 33.6 & 0.0 & 100.0 \\
\hline Clinics & 7,000 & 53.8 & 46.2 & 0.0 & 46.2 & 0.0 & 0.0 & 100.0 \\
\hline Private registered & 87,800 & 41.5 & 58.5 & 3.4 & 26.4 & 28.6 & 0.0 & 100.0 \\
\hline Hospitals & 14,800 & 52.0 & 48.0 & 10.9 & 15.9 & 21.1 & 0.0 & 100.0 \\
\hline $\begin{array}{l}\text { Nursing and maternity } \\
\text { homes }\end{array}$ & 66,500 & 38.4 & 61.6 & 2.1 & 26.5 & 33.1 & 0.0 & 100.0 \\
\hline Clinics & 6,500 & 50.0 & 50.0 & 0.0 & 50.0 & 0.0 & 0.0 & 100.0 \\
\hline Private unregistered & 10,500 & 62.3 & 37.7 & 0.0 & 3.6 & 34.1 & 0.0 & 100.0 \\
\hline Hospitals & 500 & 100.0 & 0.0 & 0.0 & 0.0 & 0.0 & 0.0 & 100.0 \\
\hline $\begin{array}{l}\text { Nursing and maternity } \\
\text { homes }\end{array}$ & 9,500 & 58.3 & 41.7 & 0.0 & 4.0 & 37.7 & 0.0 & 100.0 \\
\hline Clinics & 500 & 100.0 & 0.0 & 0.0 & 0.0 & 0.0 & 0.0 & 100.0 \\
\hline
\end{tabular}

Notes: $M M A=$ medical methods of abortion. $M V A=$ manual vacuum aspiration. EVA=electric vacuum aspiration.

$\mathrm{D} \& \mathrm{C}=$ dilatation and curettage. $\mathrm{D} \& \mathrm{E}=$ dilatation and evacuation. $\mathrm{CHC}=$ community health centre. $\mathrm{PHC}=$ primary health centre. Total excludes a small number of abortions provided by NGOs not included in the HFS. Numbers may not add to totals because of rounding. Proportions presented in the text, figures and tables may differ slightly because of rounding. Source: Health Facilities Survey. 
Weighted total number of treated cases of complications related to induced abortion or miscarriage, and proportion of cases by complication diagnosis, Gujarat, 2015

\begin{tabular}{lc|rrrrrrr} 
& & \multicolumn{7}{|c}{$\%$ of cases, by type of complication } \\
\cline { 3 - 10 } & $\begin{array}{c}\text { Annual no. of } \\
\text { complication } \\
\text { cases }\end{array}$ & $\begin{array}{c}\text { Incomplete } \\
\text { abortion } \\
\text { from MMA }\end{array}$ & $\begin{array}{c}\text { Incomplete } \\
\text { abortion } \\
\text { from any } \\
\text { other } \\
\text { method }\end{array}$ & $\begin{array}{c}\text { Prolonged } \\
\text { or abnormal } \\
\text { bleeding }\end{array}$ & $\begin{array}{c}\text { Infection of } \\
\text { the uterus/ } \\
\text { surrounding } \\
\text { areas }\end{array}$ & $\begin{array}{c}\text { Injuryl } \\
\text { perforation/ } \\
\text { laceration }\end{array}$ & Sepsis & Shock \\
\hline Facilities & 105,900 & 48.5 & 22.0 & 30.8 & 8.9 & 3.1 & 3.7 & 3.4 \\
Public & 20,300 & 43.5 & 29.2 & 31.6 & 11.4 & 5.3 & 7.5 & 3.3 \\
Private & 85,600 & 49.6 & 20.3 & 30.6 & 8.3 & 2.6 & 2.8 & 3.4 \\
\hline
\end{tabular}

Notes: More than one type of complication may be reported per case. Proportions presented in the text, figures and tables may differ slightly because of rounding. Source: Health Facilities Survey. 
Profile of married women aged 15-49* and of those who had an abortion in the three years preceding the survey, Gujarat, 2015-2016

\begin{tabular}{|c|c|c|c|c|c|c|}
\hline \multirow[b]{2}{*}{ Characteristic } & \multicolumn{3}{|c|}{ All women $15-49$} & \multicolumn{3}{|c|}{ Women 15-49 who had an abortion } \\
\hline & $\begin{array}{c}\% \\
\text { distribution }\end{array}$ & Weighted no. & $\begin{array}{c}\text { Unweighted } \\
\text { no. }\end{array}$ & $\begin{array}{c}\% \\
\text { distribution }\end{array}$ & $\begin{array}{l}\text { Weighted } \\
\text { no. }\end{array}$ & $\begin{array}{c}\text { Unweighted } \\
\text { no. }\end{array}$ \\
\hline \multicolumn{7}{|l|}{ Residence } \\
\hline Urban & 44.4 & 10,188 & 8,202 & 57.6 & 67 & 51 \\
\hline Rural & 55.6 & 12,744 & 14,730 & 42.4 & 49 & 55 \\
\hline \multicolumn{7}{|l|}{ Caste/tribe } \\
\hline Scheduled caste & 11.4 & 2,610 & 2,567 & 11.7 & 14 & 14 \\
\hline Scheduled tribe & 14.7 & 3,370 & 5,096 & 15.3 & 18 & 18 \\
\hline Other Backward Class & 43.3 & 9,934 & 9,536 & 38.1 & 44 & 43 \\
\hline Other/none & 30.6 & 7,018 & 5,733 & 34.2 & 40 & 30 \\
\hline \multicolumn{7}{|l|}{ Age-group } \\
\hline$<20$ & 16.2 & 3,708 & 3,782 & 3.9 & 5 & 6 \\
\hline $20-24$ & 16.7 & 3,825 & 3,865 & 17.5 & 20 & 25 \\
\hline $25-29$ & 15.5 & 3,552 & 3,497 & 37.1 & 43 & 35 \\
\hline $30-34$ & 15.0 & 3,438 & 3,421 & 26.1 & 30 & 24 \\
\hline$\geq 35$ & 36.6 & 8,409 & 8,367 & 15.3 & 18 & 16 \\
\hline \multicolumn{7}{|l|}{ Births } \\
\hline 0 & 29.9 & 6,850 & 6,809 & 22.9 & 27 & 27 \\
\hline 1 & 15.2 & 3,485 & 3,357 & 29.7 & 35 & 36 \\
\hline 2 & 26.3 & 6,040 & 5,971 & 23.1 & 27 & 23 \\
\hline$\geq 3$ & 28.6 & 6,557 & 6,795 & 24.3 & 28 & 20 \\
\hline \multicolumn{7}{|c|}{ Marital duration (in years)* } \\
\hline $0-2$ & 11.2 & 1,923 & 1,881 & 13.7 & 15 & 18 \\
\hline $3-5$ & 11.7 & 2,024 & 2,033 & 25.1 & 28 & 22 \\
\hline $6-15$ & 34.3 & 5,903 & 5,900 & 49.9 & 56 & 50 \\
\hline$\geq 16$ & 42.8 & 7,382 & 7,412 & 11.3 & 13 & 10 \\
\hline \multicolumn{7}{|l|}{ Education (in years) } \\
\hline 0 & 22.8 & 5,240 & 5,708 & 15.1 & 18 & 14 \\
\hline $1-5$ & 12.7 & 2,919 & 2,996 & 20.3 & 24 & 24 \\
\hline $6-11$ & 43.9 & 10,075 & 10,102 & 43.0 & 50 & 43 \\
\hline$\geq 12$ & 20.5 & 4,698 & 4,126 & 21.6 & 25 & 25 \\
\hline Total & 100.0 & 22,932 & 22,932 & 100.0 & 117 & 106 \\
\hline
\end{tabular}

*Six unmarried women were included in the survey. They were excluded from the "marital duration" measure. Note: Proportions presented in the text, figures and tables may differ slightly because of rounding. Source: reference 30 . 
Calculations for the medium, low and high estimates from the sensitivity analysis of the total incidence and rate of induced abortion, Gujarat, 2015

\begin{tabular}{|c|c|c|c|}
\hline Data inputs & Medium & Low & High \\
\hline Total for-profit MMA sales (after applying grouped rates) ${ }^{*}$ & 417,800 & 414,100 & 422,400 \\
\hline No. of combipacks and mifepristone pills sold in for-profit setting $†$ & 65,600 & 65,100 & 66,200 \\
\hline Grouped states MMA rate $\ddagger$ & 24.5 & 24.3 & 24.8 \\
\hline Total nonprofit MMA sales§ & 359,300 & 359,300 & 359,300 \\
\hline Total adjusted sum of for-profit and nonprofit MMA sales & 693,200 & 664,900 & 724,100 \\
\hline Adjustment to account for wastage $\mathrm{e}^{\star *}$ & 77,700 & 77,300 & 78,200 \\
\hline $\begin{array}{l}\text { Adjustment to exclude women who used MMA unsuccessfully outside a } \\
\text { facility and then had a facility-based abortiont† }\end{array}$ & 6,100 & 8,000 & 2,900 \\
\hline TOTAL NONFACILITY MMA & 647,900 & 619,600 & 678,700 \\
\hline $\begin{array}{l}\text { Adjustment to exclude MMA in private and NGO facilities (from HFS } \\
\text { and NGO service statistics) from adjusted total sales }\end{array}$ & 43,500 & 43,500 & 43,500 \\
\hline $\begin{array}{l}\text { Adjustment to exclude MMA given by prescription in public facilities } \\
\text { from adjusted total sales }\end{array}$ & 1,800 & 1,800 & 1,800 \\
\hline TOTAL FACILITY-BASED ABORTIONS (MMA AND SURGICAL) & 122,000 & 99,400 & 144,700 \\
\hline \multicolumn{4}{|l|}{ TOTAL NONFACILITY ABORTIONS USING METHODS OTHER } \\
\hline THAN MMAł‡ & 41,900 & 22,200 & 62,000 \\
\hline TOTAL INDUCED ABORTIONS & 811,800 & 741,200 & 885,400 \\
\hline Induced abortion rate (abortions per 1,000 women aged 15-49) & 47.6 & 43.5 & 51.9 \\
\hline
\end{tabular}

*For-profit MMA sales come from IMS Health. The estimated total count for each state was increased by $5 \%$ to account for incomplete coverage (applied to low, medium and high estimates). †Medium estimate assumes (based on expert opinion and literature) that $80 \%$ of women using MMA to induce abortion use one mifepristone pill, $10 \%$ use two and $10 \%$ use three; low estimate assumes ratio of 70\%/15\%/15\%; high estimate assumes ratio of $90 \% / 5 \% / 5 \%$. $¥ G u j a r a t$ was grouped with Chandigarh, Delhi, Goa, Haryana, Himachal Pradesh, Jammu \& Kashmir, Madhya Pradesh, Maharashtra, Punjab, Rajasthan and 23\% of Uttar Pradesh, and we calculated a rate (for-profit MMA sales per 1,000 women aged 15-49) for the group of states. The group rate was then applied to population numbers of each state in the group to obtain the number of for-profit MMA sales in each state. §Data primarily from Marie Stopes International and DKT International. Count is comprehensive, with no range around the medium estimate. ${ }^{*}$ On the basis of available literature sources, we estimate drug wastage to reduce the number of MMA packets by $10 \%$ (medium estimate), $13 \%$ (low) or $7 \%$ (high). ††On the basis of a study of abortion seekers in two states, we estimate the proportion of all facility-based abortion clients who attempted an MMA outside a facility before obtaining an abortion in a facility to be $5 \%$ (medium estimate), $8 \%$ (low) or $2 \%$ (high). ¥¥On the basis of communitybased studies in two states and national data on the increase in MMA sales between 2009 and 2015, we estimate the proportion of abortions in this category to be $5 \%$ (medium estimate), $3 \%$ (low) or 7\% (high). Notes: See Incidence Methodology and online methodology (“supplementary materials" at https://www.thelancet.com/journals/langlo/ article/PIIS2214-109X(17)30453-9) for sources and more details. Total facility-based abortions include a small number of abortions provided by NGOs not included in the HFS. Calculations based on a projected 2015 female population aged 15-49 of 17,048,928 from Census data. MMA=medical methods of abortion. HFS=Health Facilities Survey. Numbers may not add to totals because of rounding. 



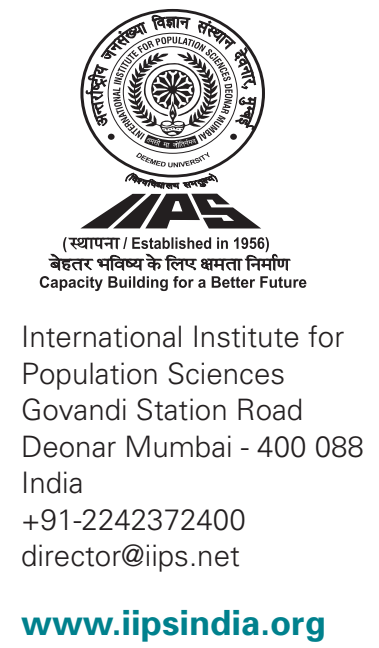

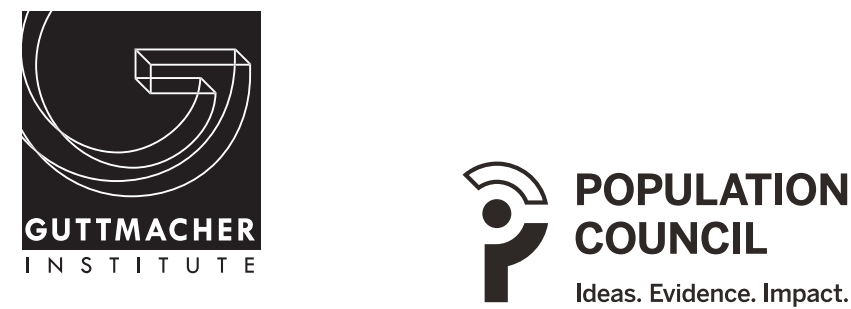

Good reproductive health policy starts with credible research

125 Maiden Lane New York, NY 10038 212.248.1111

info@guttmacher.org

www.guttmacher.org
Zone 5A, Ground Floor India Habitat Centre/Lodhi Road New Delhi - 110003 India +91-11-24642901/02 info.india@popcouncil.org www.popcouncil.org 